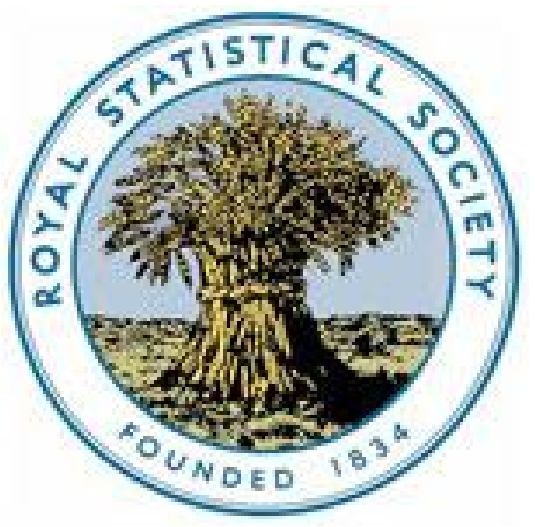

\title{
WILEY
}

The Recent Decline in the English Death-Rate Considered in Connection with the Causes of Death

Author(s): G. B. Longstaff

Source: Journal of the Statistical Society of London, Vol. 47, No. 2 (Jun., 1884), pp. 221258

Published by: Wiley for the Royal Statistical Society

Stable URL: http://www.jstor.org/stable/2979188

Accessed: 26-06-2016 05:34 UTC

Your use of the JSTOR archive indicates your acceptance of the Terms \& Conditions of Use, available at

http://about.jstor.org/terms

JSTOR is a not-for-profit service that helps scholars, researchers, and students discover, use, and build upon a wide range of content in a trusted

digital archive. We use information technology and tools to increase productivity and facilitate new forms of scholarship. For more information about JSTOR, please contact support@jstor.org.

Royal Statistical Society, Wiley are collaborating with JSTOR to digitize, preserve and extend access to Journal of the Statistical Society of London 


\title{
JOURNAL OF THE STATISTICAL SOCIETY,
}

\author{
JUNE, 1884.
}

\section{The Recent Dechine in the English Death-Rate considered in Connection with the Causes of Death.}

\author{
By G. B. Longstaff, M.A., M.B., Oxon., M.R.C.P.
}

[Read before the Statistical Society, 18th March, 1884. The Presidnnt, Robert GIFfen, EsQ., LL.D., in the Chair.]

ONE of the most striking facts of the day, from the statistician's point of view, is the remarkably low death-rate that has prevailed in this country during the last eight years. From 1838 to 1875 inclusive the death-rate averaged $22 \cdot 3$ per thousand, but during the eight years 1876-83 inclusive, it has averaged only 20.3. The only approach to such a low mortality was in the five years $1841-45$, when the death-rate averaged $2 \mathrm{I}^{\circ} 4$; so that the recent low rate is both considerably lower and extends over a greater number of years.*

Mr. Noel A. Humphreys in his paper last session proved conclusively that if the English death-rate should continue at the low average of the five years 1876-80, the mean duration of male life in this country wonld be increased by 2.0 years, and that of female life by no less than 3.4 years as compared with the English Life Table. Moreover, among males 70 per cent., and among females $65 \mathrm{per}$ cent. of this increased life would be lived between the ages of 20 and 60 years, or during the most useful period.

At Mr. Humphreys's request I have taken up the question where he left it, and have examined the changes that have taken place in the death-rates at different ages in the two sexes from various causes of death. The subject is intricate, surrounded with difficulties, and though entailing considerable labour, is perhaps not productive of adequate results. I have to thank Mr. Humphreys and his colleagues at the General Register Office for help in many ways, but must take upon myself the entire responsibility for the accuracy of the figures put forward, and the conclusions drawn therefrom. The somewhat voluminous tables no doubt contain

* (Forty-fourth Annual Report of the Registrar-General, p. xliii ; Quarterly Return of Marriages, \&c., No. 140, p. ix.)

VOL. XLVII. PAR'T II. 
errors, bat I feel confident that they cannot be of much importance, since the whole of the calculations have been checked, and all unexpected results carefully re-examined. Moreover the calculations have been made by the aid of the Arithmometer of M. Thomas, which, in my hands at any rate, gives more accurate results than logarithmic computation, besides being infinitely less laborious.

As I shall have to deal entirely with the Registrar-General's Returns, it is well that I should say in limine that after carefully reading all that has been advanced in recent years against "The "National System of Vital Statistics," I am thoroughly convinced of the soundness of that system and the fallacies inherent in all attacks upon it. Moreover, having studied for several years the figures relating to "Alleged Causes of Death," I have been more and more convinced of the value of those figures, and I fully believe that they may be taken as, on the whole, a fair approxirnation to the truth. At the same time it is hardly necessary to say that like all other statistics they require care and knowledge in handling. Without doubt the figures relating to alcoholism, venereal diseases, and perhaps insanity, are almost valueless; but that does not prove that those relating to scarlet fever, pneumonia, or cancer are equally valueless. Neither does the fact that a large number of certificates are carelessly filled up, invalidate the yet larger number that are more trustworthy: indeed these very sources of error are subject to laws, and are more or less constant factors of the whole. When it is possible, as I have elsewhere* proved it to be, to find general laws regulating many of the causes of death, and especially mutual relations between these causes, and relations between some of them and various external phenomena, the only possible inference that $I$ can deduce is that the figures dealt with are the expression more or less accurate of facts in nature. The national importance of the subject must be my excuse for this digression.

But in spite of what $I$ have just stated, it must be admitted that there are numerous fallacies to which the classification of deaths according to their alleged causes is liable. They are :-

Firstly, in a number of cases no cause of death is specified at all. In 1847 about 5 per cent. of the deaths came under "cause " unspecified," but in 1880 this proportion was reduced to less than I per cent. (Annual Reports of the Registran-General.)

Secondly (and this is a much more important source of error), in a larger number of cases the canse is stated in such a vague or indefinite manner as to be almost valueless. The terms atrophy,

* Transactions of the Society of Medical Officers of Health, 1879-80, p. 44; ditto, 1880-81, p. 45. Transactions of the Epidemiological Society of London, vol. iv, p. 421; ditto, New Series, vol. ii, p. 119. 
debility, old age, hæmorrhage, dropsy, \&c., give but little information, but it is satisfactory to note that, from the commencement of the reports in 1838 to that last issued, the improvement in this respect is steady and continuous. For example very few cases are now returned simply as "dropsy," but the dropsy is referred to disease of the heart, kidneys, liver; or ovaries.

Thirdly, where the cause is definitely assigned there is good reason to believe that in a large number of cases owing to carelessness, ignorance, a desire to spare the feelings of relatives, or even less worthy motives, the causes of death assigned are barely approximately correct. The returns themselves indicate that this source of error is also diminishing.

Fourthly, medical science like most other things is more or less under the dominion of fashion, hence the same disease is at different times given different names. By the aid of a little medical knowledge this can to a large extent be allowed for.

Before entering into fuller detail it will be convenient, with.ut taking into account sex and age, to ascertain what alleged causes of death appear to be growing more and more potent, and what on the other hand are less and less frequently assigned.

For this purpose we may utilise Table XXXIV in the RegistrarGeneral's Forty-third Annual Report. In this are given the mean annual rates of mortality for each period of five years from 1850-79. From it the following table is constructed :-

Table A.-Rise or Fall in the Death Rates per 1,000,000 Persons Living in England and Wales, from Various Causes or Groups of Causes. Averages of Quinquennium 1875-79, compared with Averages of Quinquennium 1850-54.

\begin{tabular}{|c|c|c|c|}
\hline \multicolumn{2}{|l|}{ Risen per $1, \infty \infty, \infty \infty$ Living. } & \multicolumn{2}{|l|}{ Fallen per $1, \infty \infty, \infty \infty$ Living. } \\
\hline 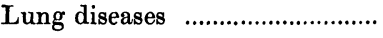 & 1,213 & 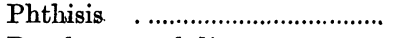 & 694 \\
\hline Heart $\quad, \quad$ & 696 & Developmental diseases .............. & 617 \\
\hline 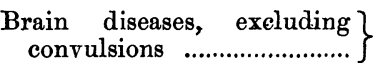 & 377 & $\begin{array}{l}\text { Fever } \\
\text { Dropsy }\end{array}$ & $\begin{array}{l}569 \\
405\end{array}$ \\
\hline 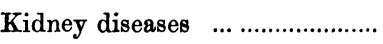 & 229 & 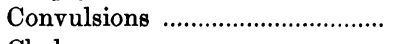 & 342 \\
\hline 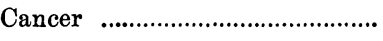 & I9I & 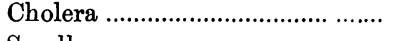 & 287 \\
\hline Liver diseases ................................. & 76 & $\begin{array}{l}\text { Small pox } \\
\text { Scarlet fever }\end{array}$ & 197 \\
\hline Diphtheria and croup .................. & 69 & Diseases of stomach and & 173 \\
\hline Tabes mesenterica & 65 & intestines $\ldots \ldots \ldots \ldots \ldots \ldots \ldots$ & \\
\hline Whooping cough & 45 & 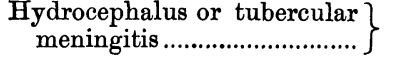 & I I I \\
\hline 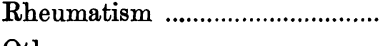 & 45 & Sudden death-cause un- & \\
\hline 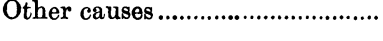 & 196 & ascertained & 101 \\
\hline Total rise ....................... & 3,202 & Diarrncea & $\begin{array}{l}85 \\
64\end{array}$ \\
\hline Balance, fall .................. & $\mathrm{I}, 049$ & 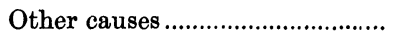 & 494 \\
\hline & & Total fall ......... & $4,25^{I}$ \\
\hline
\end{tabular}

82 
This table suggests several remarks. In the first place it will be noticed that six so-called " zymotic diseases," viz., fever, cholera, small pox, scarlet fever, diarrhœea, and measles, between them contribute a fall of 1.,375 deaths per million, against which there is a set off of I I $_{4}$, being the rise under the heads of diphtheria, croup, and whooping cough, leaving a net fall of 1,261 deaths per million from the principal zymotic diseases. But as the total fall from all causes is 1,049 , it is evident that the deaths from non-zymotic diseases must have risen 212 per million.

The increased mortality from lung diseases is remarkable. It will be shown in the sequel that this is not to be explained by the fall in phthisis, even were that fan large enough to explain it. Doubtless, however, some of the cases (but not very many) now classed under bronchitis would have been attributed to phthisis thirty years ago ; also some cases formerly attributed to old age alone are now more properly classed under diseases of lungs, brain, or kidneys. Among the diseases of the nervous system there is a fall under the vague term "convulsions" in the first few years of life, nearly as great as the rise under the other members of the group at later ages.

Now it is obvious that errors due to all the four causes mentioned above, and more especially errors due to changes in nomenclature and classification, will be minimised by comparing two periods as near together as possible, and for my present purpose it is convenient to take the periods 1861-70 and 1876-80. The facts for the first period are at once available in Tables $\mathbf{2}$ and 3 of the Supplement to the Thirty-fifth Annual Report of the Registrar-General, which give the death-rates for males and females separately, from all causes, and twenty-five separate causes, at twelve groups of ages. My tables differ from these in the following respects:-

(1.) The rates are per 100,000 living at each age, instead of per million, as I believed that the essential features would be rendered somewhat more clearly by the use of fewer figures.

(2.) I group all ages above 75 together, since the returns of ages of very old people are untrustworthy, and the numbers are small.

(3.) In place of twenty-five causes or groups of causes I have only used fifteen. This was done mainly to save labour, but partly because some of the causes given by the Registrar-General, such as " diseases of the skin," were unimportant for my purpose. If it had been practicable without very great labour, I should have preferred to separate "convulsions" from other brain diseases, and liver diseases from those of the stomach.

With the figures so obtained I have compared like rates for the 
five years 1876-80. These rates were laborionsly calculated from the number of deaths given in each annual report, which had to be cast and the average taken. At first I had wished to take advantage of the 1881 report, issued since Mr. Humphreys's paper, but decided not to do so, for it seemed best to consider the same years as he did; moreover, the classification of causes of death was altered in 1881 in such a way that I found the labour greatly increased when I began by including that year.

Tables I-IV form a double set, $\mathrm{I}_{A}, \mathrm{II}_{A}$, \&c., relating to males, $\mathrm{I}_{\mathrm{B}}, \mathrm{II}_{\mathrm{B}}$, \&c., to females. All four tables relate to the same facts, namely, the average annual number of deaths in England and Wales from certain causes at certain ages. The italic type refers to the ten years 1861-70, and the roman type to the five years 1876-80.

Tables $I_{\mathrm{A}}$ and $\mathrm{I}_{\mathrm{B}}$ give the actual average deaths.

Tables II $\mathrm{A}$ and IIB give the death-rates per 100,000 living at each age.

Tables IIIA and IIIr give the percentuge rise or fall of the deathrates in the second period as compared with the first.

Tables IVA and IVB give the gain or loss in lives per annum consequent on such fall or rise in the death-rate.*

By the use of the four tables together it is hoped that the real importance or otherwise of the fluctuations will be shown. An example will make my meaning clear. Among females over 75 years of age the death-rate from diphtheria fell 40 per cent.: the consequent gain was only one life per annum. Among females between 45 and 55 years of age the mortality from lung diseases rose 5 per cent.: the consequent loss of lives amounted to 126 per annum.

In the examination of these tables it will be convenient to consider those causes of death first which Table A shows to have been long decreasing in fatality, and subsequently those which appear to have increased.

Phthisis, or pulmonary consumption, is very fatal at all ages from 15 to 75 , but most so between 20 and 55 ; at ages $5-20$ it is more fatal to females than to males, after 45 it is more fatal to men. The death-rate has declined at every age with some insignificart exceptions in both sexes: the decline being for males 14, for

* Tables IA and IB are derived from the Supplement to the Thirty-fifth Annual Report of the Registrar-General, p. 2, and from the Annual Reports for $1876-80$, pp. 146 et seq. in each report. Tables II $A$ and IIB are derived in part from Tables 2 and 3 in the Supplement to the Thirty-fifth Annual Report, in part are calculated from Tables $I_{A}$ and $I_{B}$ by the aid of the populations at each age given in the census, from which mean populations for the period in question were calculated. Tables IIIA and IIIB, IVA and IVB are derived from the preceding tables by calculation. 
females 22 per cent. For both sexes the decline was greatest (28 per cent.) between the ages of 15 and 20, when deaths may he considered, in an economic sense, the greatest loss, since the individual of that age has been supported by society for a great number of years, but has as yet done but little in return. The decline has been not much less considerable among both males and females at all other ages below 25, varying from 18 to 26 per cent. The mortality of males above 35 has diminished very little, but that of females has fallen between 14 and 24 per cent. until the age of 75 , after which there is a trifling rise. The lives saved amounted to 3,966 males, 6,806 females; not less than 2,885 of the former and 4,233 of the latter were of ages $15-35$, that is say were among the most useful of the community. The question has often been considered as to how this well known fall in the mortality from phthisis is due to "medical fashion," that is, how far it may be a mere question of classification, since it is equally well known that the mortality assigned to the diseases of the respiratory organs (principally bronchitis) is increasing. Now there are two answers to this question. Firstly, it would appear that the discovery of the so-called bacillus of tubercle would confirm the opinions of the older writers that phthisis is a distinct disease sui generis, with many forms of manifestation, and not an ill-assorted mixture of unrecognised diseases as has been more lately taught. Secondly, there is an argument that is more in place here: the mortality from phthisis is shown by the table to have diminished at the ages 5-35 to an extent varying from i 5 to 28 per cent., whereas at all these ages the mortality from diseases of the lungs remained comparatively stationary. This is especially well seen in Tables IVA and IVB. I have elsewhere ["Transactions of the Epidemiological "Society of London," N.S., vol. ii, p. 119] shown other reasons for believing that substantially the diagnosis of phthisis from bronchitis corresponds with nature. We must therefore credit medicine, whether preventive, curative, or both, with another triumph here; and let it be remembered that this triumph means saving many lives when they are most valuable. There is still ample material to work upon, plenty of room for further improvement.

Developmental diseases come next in the list of those that have decreased in fatality during the last three years. In the tables these fall under class "all other causes." The most important of these are "atrophy and debility," which relate almost entirely to young infants, and "old age," which explains itself. "All other "causes" account for about one-third of the deaths of children under 5 , about half the deaths over 75 years. The death-rate has fallen II per cent. for males and 13 per cent. for females, and 
the fall has taken place at every age of both sexes; this fall is tolerably even throughout, at least it does not exhibit the marked preference for the two extremities of life which might have been expected. The "lives saved" number 8,425 males, 9,837 females; of these numbers 4,346 males and 4,372 females are in the first five years of life, and may be fairly attributed to the better management of.children and improved sanitary surroundings, which have diminished the deaths under the vague headings " teething," "atrophy," and the like. Of the rest 2,431 males and 3,586 female lives saved are at ages over 65 , at which period there is a large increase of deaths from "local diseases" as they are called. Diagnosis is now more accurate, and certificates are more carefully filled up, hence fewer deaths are attributed to "old age."

"Fever" comprises typhoid or enteric fever, now the most important by far; typhus fever, which is still prevalent to some extent in Ireland, and lingers in the Irish quarters of Glasgow, Edinburgh, and Iiverpool ; and some less defined diseases numerically not very important. Fever kills males and females about equally, and at all ages, the two extremes of life suffering somewhat more severely. The percentage fall in the death-rate is very remarkable, being no less than 57 per cent. for each sex, the fall being spread over all ages, though old people gain most; the number of "lives "saved" is no less than 6,188 males and 6,510 females yearly; the salvage being greatest under 5 years of age, but very considerable at each age below 75. It seems impossible to dissociate this great saving of life from the operations of the public health Acts, and more especially the indirect results of this as shown in the proceedings of the Sanitary Institute, the exhibitions of sanitary appliances under various auspices, and other proofs that public attention has been drawn to these matters. The fall in the deathrate from fever is without doubt the great triumph of the sanitary reformers. Typhus has been driven out from place after place by measures taken to check overcrowding and want of ventilation (which have been to a great extent successful, although the pamphlet literature of the past autumn has no doubt caused a general impression to the contrary), until it now only lingers in the lowest quarters of a few large towns. Things are not perfect yet, far from it, bat they were once mach worse, and that not so long ago. On the other hand measures directed to improve drainage and water supply have been most successful in restraining enteric fever within comparatively narrow limits.

Dropsy. All that need be said about this is that in $1850 \mathrm{9,981}$, or 2.8 per cent., of the total deaths had this cause assigned, whereas in 1880 only $3,19^{2}$, or 0.6 per cent., of the total deaths were so classed. This does not mean that fewer persons die of dropsy than then, but 
that the dropsy itself is now more commonly attributed to its proximate cause, disease of the heart, kidneys, liver, or ovaries, or cancer. In the tables dropsy is included under "Heart diseases," but it has now ceased to play such an important part among the assigned causes of death as seriously to affect the correctness of the returns.

Convulsions are included in the tables under brain diseases.

Scarlet fever has diminished notably, but from its usually occurring in epidemics, which are possibly influenced by meteorological conditions, it is not safe to draw conclusions as to the future. It is of course a disease of childhood, most of its victims falling before the age of puberty.

In both small pox and diphtheria there has been saving of life, but these diseases now cause such small mortality that their total extinction would only reduce the general death-rate by 0.2 per 1,000 .

The diarrhoee figures are confused by the occurrence of the epidemic of Asiatic cholera in 1866. Diarrhœea kills mostly at the extremities of life, cholera has not this marked preference. This explains the fact that under diarrhoeal diseases the fall of the deathrate is greatest from 5-75. There is room for great improvement under this head.

The mortality from measles has diminished notably, but whooping cough has been stationary. Whooping cough is much more fatal to girls than to boys. Measles causes nearly five times, and whooping congh nearly six times as many deaths as small pox, while the amount of mischief to be attributed to these littlethought-of ailments in the way of impaired general health, permanent lung disease, and even blindness and deafness, will probably never be known. It would appear that as yet preventive medicine has failed to control these diseases; can this be because the people will not co-operate to put down diseases which only affect young children?

Turning now to the other side of the account, first in importance come lung diseases. Like diseases of the brain, and in contrast with phthisis, they are most fatal in the first five years of life and after 45. Again, lung diseases are 21 per cent. more fatal to males than to females, but this difference does not apply to the ages 5-20, as boys do not appear to suffer more than girls. In the case of phthisis it may be remembered the mortality of females from 5-20 exceeds that of males at the same ages. Lung diseases have increased in the period under consideration, among males 13 , among females 14 per cert.; the increase being mainly in the first five years of life and after 35 . There is a slight fall among boys of 10-15, a more marked fall among girls and young women from 
10-25. The annual "loss of lives" from these diseases amounts to 6,490 males and 5,404 females ; of these 3,486 males and 2,557 females were under 5 years old, while 2,9 19 males and 2,952 females were aged 35 years and upwards. The extra deaths among women of 65 years of age and upwards amounted to 2,267 against 1,544 among males of like ages. Doubtless at both extremes of life there has been a transference from such assigned causes as "atrophy" and " old age," or "debility of age," to bronchitis and other diseases of the lungs.

Heart Diseases and Dropsy. - It is necessary to take these together, since Dr. Farr did so in the table which I have adopted as my standard. In the first period dropsy made up 25 per cent. of the whole, in the second period only 10 per cent. But as in a large proportion of the cases (Dr. Havilland put it at three-fifths of the whole number) the dropsy was certainly caused by heart disease, the error dae to grouping the two together is not important. Females suffer from heart disease somewhat more than males, but in both cases the death-rate is much higher after 35 than before. The mortality of males has increased I 4 per cent., of females only I1. In both cases there has been a notable fall at the earlier ages, but a considerable increase, greatest in males, after the age of 35 . Whereas 344 male and $\mathbf{2 4 2}$ female lives have been saved before the age of 20 , at all ages over 20 no less than 2,909 male lives and 2,363 female lives have been lost annually in the latter as compared with the former period in the tables. Corresponding with this increase is an increase (not shown in the tables) in deaths from rheumatic fever, which is a most fruitful cause of heart disease.

Brain Diseases.-These affect males considerably (2 I per cent.) more than females; they are most fatal at the extremes of life. The mortality at all ages has not materially altered, but it is very different when the separate ages are considered. In the first five years the male death-rate has fallen 13 per cent., the female 15 per cent. This we know from other sourees* to be very largely due to the fall in "convulsions." In contrast with this at all ages over 35 there is a rise among both males and females of from 5 to 22 per cent. On one hand 2,443 male children and 2,227 female children that would have died annually from diseases of the nervous system under the death-rate prevailing in 1861-70, now survive under the rates prevailing in $1876-80$; but on the other hand at ages over 35 no less than 2,098 males and 2,078 females now die that would have survived, or died of some other cause under the former régime.

Kidney diseases are in both sexes most fatal in middle and

* “Forty-fourth Annual Report of Registrar-General," Table 33. 
advanced life; they are about twice as fatal to men as to women. Female mortality has, however, increased nearly twice as much under this head as male, although the increase is very great in all cases, varying from 20 to $8 \mathrm{I}$ per cent. The total loss of life from renal disease amounts to 1,702 males and 1,417 females, mainly in middle and advanced life.

Cancer, in contrast to renal disease, is twice as fatal to women as to men; it is rare in early life, but steadily increases in frequency from the age of 25 upwards. Cancer has increased $3^{8} \mathrm{per}$ cent. in males, 24 per cent. in females, the greater increase in males being probably due to the fact that cancer of the stomach and liver, which is commoner in men than women, is much more difficult of diagnosis than cancer of the female breast or of the uterus. Hence improved medical skill affects the returns for it more. The loss of life due to the increased mortality from cancer amounts to 1,187 males and I,66r females, of which seven-eighths are above the age of 45. A recent writer* said he was convinced that the long continued and steady increase of cancer was not apparent only, and accounted for by increased aceuracy of diagnosis and registration, but was an undoubted fact; the cause is quite unknown, but must probably be sought in some abnormal ciroumstances of our artificial existence. It should be remembered that very few, if indeed any, recover from this much dreaded disease, and also that it chiefly attacks after the reproductive age is past. Frorn these facts we may draw the consolation that if there are many killed, there are no wounded, and that although the tendency to cancer may be handed down to offspring, they are not born enfeebled in consequence of their parents' ailment.

As regards the other diseases in the tables, I will only remark that with trifling exceptions there is more or less gain of life under each division of each zymotic disease; also that the increased number of deaths from violence at the higher ages, accompanying a diminished death-rate at the lower ages, is a curious fact that is difficult to explain.

To make the various relations and changes above indicated more striking, I have constructed the summary Tables $V_{A}, V_{B}, V_{A}, V_{B}$, VII and VIII; $†$ showing the same facts as Tables I-IV, but for three groups of ages only. First, all under 20 years of age, or the dependent period of childhood and youth; second, active working life, the productive period, from 20 to 65 ; and third, the dependent period of old age, after 65 years. Mr. Humphreys in his corresponding period drew the line at 60 years; I could not have followed him exactly without great trouble, for reasons explained earlier.

* H. P. Dunn, F.R.C.S., in “ British Medical Journal," 1883, pp. 708, \&c.

+ These tables are all obtained from the preceding tables by calculation. 
These short tables show firstly, that in both sexes the deathrates from "all causes" below 20 had decreased considerably, between 20 and 65 they had also decreased, but much less, whereas over 65 there was a very small increase.

Secondly, the rates of decrease were largest among females, whereas the increase was largest among males.

Thirdly, the most marked increase in the death-rates from the several causes was from diseases of the kidneys, more especially among females, and next from cancer in men. So that it would appear there is a tendency for the mortality of the two sexes from these causes to approximate. It is possible that increased drinking among women may account for some of this increased fatality from kidney diseases.

Fourthly, the great decrease of mortality from fever at all ages is shown in a very striking manner.

Fifthly, Table VIII shows conclusively that increased precision in diagnosis and care in registration will not account for all the increased deaths from diseases of the lungs, brain, heart, \&c., since the increase under these heads greatly exceeds the decrease under " all other causes." The same tables show in an equally striking manner that "phthisis" and "lung diseases" in the reports indicate in the main at any rate essentially different causes of death, since the fluctuations are in no way reciprocal.

After this analysis it is possible to consider the bearing of the facts ascertained on the following problems.

Supposing that the last twenty years may be taken as a fair index of what we are to expect in the future, i.e., that those causes of death which have increased in fatality will continue to do so, or remain stationary; and conversely, those which have decreased in fatality will either become stationary or continue to decreasewhat will be the effect on-

(1.) The duration of life ?

(2.) The sex and age distribution of the population?

And (3.) The rate of increase of the population? In the last case the question of emigration will have to be considered.

(1.) Mr. Humphreys's paper, although appearing to do so, did not give a complete solution of the first problem, at least as far as a forecast of the future is considered.

It is well known to all statisticians that if an aggregate variable be made up of several component variables, which latter vary at different rates and in different directions, then, given two terms of a series, it is possible to get a nearer approximation to subsequent terms by calculating from the known variations of the components, than from the known variations of the aggregate. For example, a town is composed of, say, six wards; the population of the town 
at the present time may be calculated (as it usually is) from the known aggregate increase in the interval between the last two censuses. But a different number, and one almost certainly nearer to the truth, will be obtained if the increase (or decrease) of each ward be calculated in like manner, and the results added together. The same holds good with death-rates; the gross deathrate of either sex at a particular age is made up of a number of death-rates from different causes, some of which are falling, others rising, while others are stationary. It is therefore a point of special importance to remember that whereas a diminishing death-rate can only fall to zero, an increasing death-rate may conceivably rise indefinitely. This is well illustrated by the cases of fever and kidney diseases. In the aggregate no less than 12,698 fewer persons (in proportion to population) died from fever annually during $1876-80$ than during the period 1861-70. But as the number of annual deaths is now but 9,576, an equal further saving of life is no longer possible. On the other hand, there is no such obstacle to the mortality from kidney diseases rising again by 3,000, or indeed by 30,000 per annum. It is important therefore in "looking ahead" to remember that great saving of life can only be accomplished where there is now heavy loss of life. If small pox were extinguished to-morrow the result would be trifling compared to a fall of 50 per cent. in the mortality from whooping cough, or a fall of only io per cent. in lung diseases.

In the period under consideration the greatest gain of life has been under "all other causes," fever, phthisis, scarlet fever, and diarrhoeal diseases; under all these headings there still remains a considerable margin for profit, although this is getting narrowed in the case of fever. Scarlet fever practically is confined to the young; phthisis has special incidence on youth and early working life, and is of all diseases that which is most destructive to the most valuable lives; fever attacks those of all ages, but it is more fatal at the early ages than phthisis; "all other causes" account for many deaths of both young and old. With the exception of the last, a continued diminution of deaths from any of these causes would tend to increase the duration of active life; in the case of "all other causes" a great portion of the saving would only mean some prolongation of old age, which, as it would almost certainly be accompanied with increased vigour of the survivors, would be a benefit only in a degree less.

On the other side of the account we have diseases of the lungs, heart, and kidneys, and cancer. The three last exact most victims in middle and late life, the lives cut off by them are therefore less valuable than those that fall to phthisis; lung diseases are extremely fatal to the young as well as to the old, so 
that they have a point of resemblance to the zymotic diseases. If all these diseases should continue to increase in fatality in like manner, the result on the duration of life would be in the case of the first three to cut short its later years, in the case of diseases of the lungs to cut it short at both ends.

On the whole, balancing these results, we may safely say that if the individual causes of death alter in fatality in the future as they have done in the recent past, for a time the duration of life may continue to increase, but ultimately the tendency would be for more people to survive the dangers of childhood and adolescence, but fewer to reach old age. Useful life would not be greatly shortened, and as the proportion of persons of the reproductive age would be increased, the birth-rate would also be increased.

(2.) The "Report of the Census of 1881 " (pp. 22 and 23) calls especial attention to the importance of taking into consideration the constitution of a population as regards sex and age, before comparing its death-rate with that of another population. In illustration, the sex and age constitution of the urban and rural sanitary districts are contrasted, and it is remarked "if we take " the mean (1871-80) death-rates in England and Wales at each "age-period as a standard, the death-rate in an urban population, " as constituted above, would be $20^{\circ} 40$ per 1,000 , while the death"rate in the rural population would be $22 \cdot 83$. Such would be " their respective death-rates on the hypothesis that the urban " districts and the rural districts were equally healthy. We know, " however, as a matter of fact, that the urban death-rates instead " of being lower than rural death-rates are much higher. The "difference of healthiness therefore between the two is much "greater than the difference between their death-rates." This is a most important passage, and expresses a truth not generally known, and when known not sufficiently dwelt upon. As the work of calculating thus the "normal" death-rate of a population is somewhat laborious, it would, I think, be of great service to medical officers of health and others, if the Registrar-General's Department would publish a table of factors by which the death-rates of the principal towns ascertained in the ordinary way could be reduced to the normal (e.g., in the circumstances given, the rural factor would be 959097 , the urban factor $\mathbf{r}^{\circ} 073343$ ). The age and sex constitution of the population of England and Wales has changed, though not to a very great extent. It would be interesting to know what influence these small changes have in themselves had upon the death-rate and birth-rate.

Any one approaching the subject on $\grave{a}$ priori lines might well maintain that the agglomeration of human beings in towns affects a constantly increasing fraction of the people, and therefore since 
life in towns is necessarily less healthy than life in the country, the tendency will be for the death-rate to rise. The first proposition is undoubtedly true: the town population in 1851 was but $5^{1}$ per cent. of the whole, it is now 59 per cent., the increase has been and appears likely to be continuous.* The second premise has appeared to be true hitherto, but nevertheless the conclusion has not followed. The explanation would appear to be that the increased attention paid to hygienic matters by the individual, the corporation, and the State, has more than counterbalanced the evils attendant upon density of population. This must not, however, be pushed too far; the "sanitary" surroundings of many town populations are now superior to those of country populations, but yet the death-rates of these populations remain higher than those prevalent in the country; whereas the above extract from the last census clearly shows that owing to peculiarities of age and sex constitution they should be lower. The increased mortality from cancer and several of the "local diseases," the increase in lunacy (though this is not so great as it appears), the deterioration of eyesight, the unquestioned premature decay of the teeth of the rising generation, and to a much smaller extent the prevalence of premature baldness, convince me that the $a$ priori argument is a sound one. There are conditions attendant on life in towns which no hygienic knowledge, no improved administration, not even a new municipal government for London, can wholly overcome. Some amount of degeneration of race appears inevitable, and in the United States of America, where all sociological phenomena are seen in more rapid evolution than here, it is said to be even already very evident. This seems to be a fitting place to meet an objection that will be brought forward by many-they will say: "One thing is plain, no " sanitary improvements, no amelioration of habits, will enable men " and women to live for ever. The increased mortality from local "diseases towards the end of life is the inevitable correlative to the " diminished mortality in infancy." There is a fallacy of time inherent in this objection. The total period in review from the first year to the last only extends over twenty years, while the average interval, from the middle year of the first period to the middle year of the second is only twelve and a half years. The recent fall in the death-rate of children under 10 did not begin until the year 1867 , $\uparrow$ so that but few of the extra survivors could have attained their majority by the middle of the second period, far less could they have added some thousands annually to the deaths of persons aged 65 and upwards. Our records do not go back

" Calculated from a table in " Report, on Census, 1881," p. 9.

† "Forty-fourth Annual Report of Registrar-General," pp. lxv and lxvi. 
further than 1838. We know that during the five years 1841-45* low mortality prevailed at ages over 25 , and during the first five years of life. The younger adults of those days, if now surviving, would be old men to-day; the children then under 5 would by our second period be aged 35-40. The recent census shows it is true a slight excess of females at ages $35-45$, but males are a trifle in defect. But all this would prove nothing unless we assume, as it is perhaps reasonable, that the extra survivors are more delicate than the average, for the death-rates per thousand living have increased at the later ages. But any way this increase is small compared with what we have gained at other ages, so that the balance in our favour remains large.

Table IX $†$ shows for childhood, working life, and old age, the relative incidence of the various causes of death upon males and females. This table read together with Tables VII $\mathrm{VI}_{A}$ and VII shows which sex gains most by each change in the death-rate. Thus in childhood and youth young girls suffer especially (as compared with boys) from phthisis, whooping cough, diphtheria, fever, and heart disease, and all these have diminished in fatality. On the other hand, boys suffer especially (as compared with girls) from violence, kidney diseases, brain diseases, "all other causes," lung diseases, and to a less degree from diarrhœal diseases, small pox, measles, and scarlatina. Of these, lung and kidney diseases are increasing in fatality, the rest are declining, the net results being that girls gain more than boys in the proportion of 7 to 6 . During working life from cancer alone do women lose more than men, but here the loss is more than double, and cancer is increasing rapidly; men on the other hand suffer more especially from violence ( 5 to I), kidney diseases, lung diseases, phthisis, brain diseases, and fever. Of these, diseases of the kidneys, lungs, and brain are all increasing, the others are diminishing, but the net result shows that females gain more than males in the proportion of 7 to 3. In old age women again suffer from cancer more than men, and cancer is increasing in fatality, but on the other hand old men suffer excessively from kidney diseases ( 3 to 1 ), violence, phthisis, small pox, and fever; of these, all except phthisis and fever are increasing. In the net result the mortality of both old men and old women is increasing, but the death-rate of old men three times as fast as that of old women.

It is quite plain that the recent fall in the death-rate favours the accumulation of surplus women, if one may be allowed such an expression, and should the change of mortality go on in the same direction the rate of accumulation will be increased. Several other

* “Forty-fourth Annual Report of Registrar-Generdl," pp. lxv and lxvi.

+ Calculated from the other tables. 
factors are working in the same direction. (a.) Forty years ago for every 100 female children, 104.8 male children were born, but now the number is only 103.9.* (b.) Emigration always removes an excess of males; thus during the six years $1877-82$ no less than 349,666 adult Englishmen left this country, but they were accompanied by only 179,869 adult Englishwomen, so that the men were 169,797 in excess, or nearly 2 to r. Emigration is however to a great extent balanced by immigration. In the ten years between the two last censuses the result of migration amounted to a loss to this country of 123,467 males and 40,840 females, the excess of males being $82,627 . \dagger$ (c.) Independently of recent changes women live longer than men. $\ddagger$

The combined result of the operation of all these factors is less than might have been expected. In 1851 there were in this country 104.2 females to every 100 males. This proportion has risen gradually till it now amounts to 105.5 to $100 . \S$

As this excess of women is a common topic of conversation, I have drawn up in the interest of the ladies the following table, based on a longer table in the census report, vol. iii, p. v:-

$\mathrm{T}_{\triangle \mathrm{BBLE}}$ B.-Showing Excess of Males or Females at Different Groups of Ages, together with their Conjugal Condition.

\begin{tabular}{|c|c|c|c|c|}
\hline \multirow{2}{*}{ Ages and Condition. } & \multicolumn{2}{|c|}{ Males. } & \multicolumn{2}{|c|}{ Females. } \\
\hline & Numbers. & Excess. & Numbers. & Excess. \\
\hline Children under 15 .............. & $4,728,466$ & - & $4,740,125$ & 11,659 \\
\hline Unmarried $15-35$................ & $2,704,062$ & $\pi 2,629$ & $2,631,433$ & - \\
\hline , $\quad 35-45$ & 195,427 & - & 233,820 & 38,393 \\
\hline$", \quad 45-\ldots \ldots \ldots$ & 200,255 & - & 292,151 & 91,896 \\
\hline Married 15-35 .................... & $1,469,040$ & - & $1,778,237$ & 309,197 \\
\hline$" \quad 35-\ldots \ldots \ldots$ & $2,907,858$ & 248,133 & $2,659,725$ & \\
\hline Widowed, all ages ................ & 434,794 & - & 999,046 & 564,252 \\
\hline Total ....................... & $12,639,902$ & 320,762 & $13,334,537$ & $1,015,397$ \\
\hline Balance, excess of females & - & 694,635 & - & - \\
\hline
\end{tabular}

The discrepancy between married men and women, some 60,000 more married women than men being returned, admits of ready explanation. Many men at sea, in the army in different parts of

* “ Forty-fourth Annual Report of the Registrar-General," p. liv.

+ " Board of Trade Return on Emigration and Immigration for 1882." Also "Report on Census, 1881," p. 15.

English Life Table.

$\S$ “. Report on Census, 1881,” p. 15. 
the world, in the colonies, or travelling, had left wives at home. Some few men who had really been married no doubt found it convenient to return themselves as unmarried; probably a considerably larger number of women did the reverse. Taking no account of these, the table shows that the total excess of females, amounting to close upon 700,000, comprises 564,252 widows, a simply appalling number whether viewed from a sentimental or an economic standpoint. But this is only the excess of widows over widowers. The total number of widows is very little short of a million! (999,045). The "really old maids" number only 292, 15 I, or 91,896 more than the old bachelors; there remain 233,820 who may be termed "rather old maids." The I I,659 female children in excess to some extent correspond to the 72,629 young men in excess, since women marry earlier than men.

(3.) There remains for consideration the effect of the present or future decline of the death-rate upon the increase of the population. But little need be said on this head. It is obvious that if fewer die, more will survive, and pro tanto the population will be increased. But there is more in it than this. Clearly, everything depends upon the ages at death. It is possible to conceive two populations with equal general death-rates, but increasing at rery different rates. If the mortality falls chiefly on the earlier ages, while those who reach maturity live on to a ripe old age, a slowly increasing population will result. On the other hand, if there be a high birth-rate, accompanied with high death-rates in middle an $\mathrm{l}$ late life, the population will increase much more rapidly. 'T'he birth-rate must mainly depend upon the proportion of the population living between the ages of 20 and 40 . Now this is what all the figures show, death-rates in early life falling, in late life rising; so that the population is inereased in two ways, directly, by the diminution of deaths, indirectly, by the proportionate increase of births; or perhaps it would be more correct to say "breeding "capacity," since the birth-rate is largely influenced by the marriage-rate, which in its turn is affected by commerce. It should, however, be borne in mind that emigration, just now very active, by removing chiefly those of the breeding age, and to a less degree by increasing the disproportion of the sexes, tends to counteract this rise in the birth-rate, so that emigration checks population in two ways.

The chief inferences which I think may be fairly drawn from the facts under review, are:-

(1.) The decline of the death-rate in recent years is chiefly to be attributed to a diminished number of deaths assigned to fever and phthisis, and, to a somewhat less degree, to scarlet fever, diarrhœal diseases, small pox, diphthoria, and measles.

(2.) There is also a great diminution under the heading "all POL. XLVII. PART II. 
"other diseases," but this is largely to be explained by greater precision in filling in certificates of the cause of death, which partly accounts for the increase under certain other causes.

(3.) There has been coincidently with a fall in the general death-rate a considerable increase under certain causes of death, notably diseases of the lungs, heart, kidneys, and cancer.

(4.) The figures prove that only a portion of the increase noted under the above headings can be explained by improvement in the returns. There has been a real, not merely an apparent increase. More especially the increase under lung diseases will not explain the fall under phthisis.

(5.) The gain under phthisis is more important than the loss under cancer, kidney diseases, and some others, since the lives saved are more valuable than those lost, also in the case of phthisis parents beget children when far advanced in disease, a fact greatly to be regretted.

(6.) Preventive medicine should be especially directed against those diseases which kill the largest numbers, such as "local " diseases" generally, the ill defined diseases of infancy and phthisis; while among the zymotic diseases, diarrhooa and scarlet fever, whooping cough and measles, are more important than diphtheria and small pox.

(7.) Since the falling causes of death ean only fall to zero, but the rising causes may rise indefinitely, the present changes may in course of time lead to a rise in the general death-rate.

(8.) The tendency appears to be for useful working life to be increased, but for old age to be slowly shortened.

(9.) The increased mortality in the latter years of life, and such phenomena as the increase of defective sight and rapid deterioration of the teeth, probably result from the increasing proportion of the population living under the artificial conditions of town life.

(10.) The present increased mortality at the higher ages cannot possibly be explained by the recent diminished mortality at the beginning of life, even on the supposition that the survivors are more delicate.

(11.) The changes that are taking place in the incidence of mortality, almost all aid the other causes which contribute to the great superabundance of women in England and Wales.

(12.) They also tend to increase population both by diminution of deaths, and increase, positively and relatively, of births.

In conclusion, if $I$ have made mistakes in my figures, or if $I$ have been over-ready in connecting cause and effect, I must ask you to make allowance for the complexity of a problem which is bound up with so many of the infinite relations of civilised life, an equation in which the number of unknown quantities is itself unknown. 
Table IIIA.*-England and Wules. Males. Percentage Fall or Rise in the Death-Rates from Various Causes at Eleven Groups of Ages, Average of the Five Years. 1876-80, compared with Average of the Ten Years 1861-7().

\begin{tabular}{|c|c|c|c|c|c|c|c|c|c|c|c|c|}
\hline & $\begin{array}{c}\text { All } \\
\text { Ages. }\end{array}$ & 0 - & $5-$ & $10-$ & $15-$ & $20-$ & $25-$ & $35-$ & $45-$ & $55-$ & $65-$ & $75-$ \\
\hline 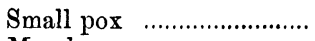 & -49 & -73 & -47 & -9 & 23 & -30 & -16 & -14 & -12 & $-35|-|$ & -39 & \\
\hline .............. & -12 & -1 & & -8 & -33 & & & $\ldots$ & $\ldots$ & $\ldots$. & $\ldots$ & .... \\
\hline Scarlet fever ........................ & -30 & -29 & -31 & -40 & -38 & -40 & -34 & -9 & & $\cdots$ & $\ldots$. & \\
\hline 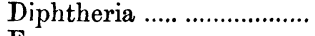 & -34 & -39 & -22 & -28 & -53 & -51 & -50 & -25 & -36 & -37 & -39 & -7 \\
\hline ........................... & -57 & -59 & -56 & -50 & -47 & -43 & -49 & -60 & -63 & -69 & -71 & -71 \\
\hline $\begin{array}{l}\text { ooping cough } \\
\text { rhoeal diseases }\end{array}$ & $\begin{array}{l}+1 \\
-20\end{array}$ & $\begin{array}{l}+1 \\
-12\end{array}$ & $\begin{array}{l}-2 \\
-63\end{array}$ & -77 & -74 & -73 & 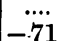 & -60 & $\ldots$ & $-\ddot{41}$ & $\begin{array}{c}\cdots \\
-32\end{array}$ & \\
\hline & & & & & & & & & & & & \\
\hline & -14 & -23 & -20 & -23 & -28 & -26 & -15 & -4 & & & & \\
\hline ....... & +13 & +17 & +2 & -3 & +3 & -1 & +5 & +14 & +14 & +10 & +11 & +2 \\
\hline ..................... & -2 & -13 & +4 & +1 & -5 & -14 & -6 & +5 & +9 & +16 & +16 & +2 \\
\hline es and dropsy & +14 & -30 & -30 & -11 & $\ldots$ & +3 & & +28 & +22 & +22 & +21 & +2 \\
\hline ases ...................... & +32 & +68 & +48 & +23 & +20 & +23 & +27 & +33 & +40 & +40 & +30 & +2 \\
\hline 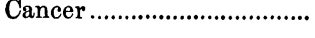 & +38 & & & & & & +18 & +25 & +38 & +43 & +52 & +44 \\
\hline 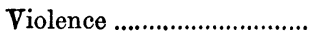 & -8 & -10 & -16 & -27 & -17 & -13 & -9 & -6 & +2 & +4 & +10 & +19 \\
\hline All other causes..................... & -11 & -10 & -12 & -9 & -8 & -12 & -11 & -9 & -6 & -9 & -16 & -10 \\
\hline All causes ....................... & -7 & -9 & -23 & -23 & -22 & -21 & -12 & -1 & +3 & +5 & & +1 \\
\hline
\end{tabular}

Tabie IIIв. --England and Wales. Females. Percentage Fall or Rise in the DeathRates from Various Causes at Eleven Groups of Ages, Average of Five Years 1876-80, compared with Average of Ten Years 1861-70.

\begin{tabular}{|c|c|c|c|c|c|c|c|c|c|c|c|c|}
\hline & $\begin{array}{c}\text { All } \\
\text { Ages. }\end{array}$ & 0 - & 5 - & $10-$ & $15-$ & $20-$ & $25-$ & $35-$ & $45-$ & $55-$ & $65-$ & $75-$ \\
\hline 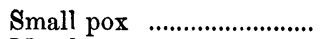 & -50 & -74 & -51 & -5 & -15 & -1 & -7 & +14 & +6 & -4 & -13 & -12 \\
\hline 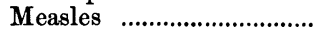 & -14 & -14 & -11 & -28 & -31 & -30 & -11 & & $\sigma^{\circ}$ & $\ldots$. & $\ldots$ & $\ldots$. \\
\hline 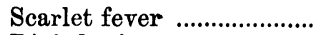 & -31 & -29 & -33 & -48 & -45 & -41 & -30 & -21 & & & $\ldots$ & \\
\hline 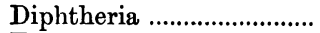 & -34 & -39 & -26 & -37 & -39 & -44 & -39 & -18 & -50 & -32 & -14 & -40 \\
\hline 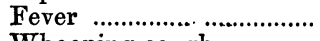 & -57 & -61 & -55 & -50 & -49 & -50 & -49 & -61 & -65 & -69 & -70 & -76 \\
\hline 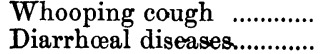 & $\begin{array}{l}-1 \\
-29\end{array}$ & {$\left[\begin{array}{l}-1 \\
-14\end{array}\right.$} & -12 & -66 & $\dddot{70}$ & $\ldots$ & $\ldots$ & $\cdots$ & $\ldots$ & 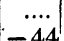 & $\cdots$ & $\cdots$ \\
\hline Diarrhœal diseases............. & & & & -66 & & -66 & -67 & -64 & -56 & -44 & -34 & -24 \\
\hline Phthisis & -22 & -22 & -19 & -18 & -27 & -26 & -24 & -16 & -17 & -16 & -14 & +2 \\
\hline Lung diseases ........ & +14 & +15 & +1 & -9 & -12 & -9 & $\ldots$ & +12 & +5 & +8 & +15 & $+3 \overline{3}$ \\
\hline 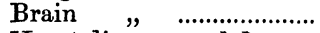 & -1 & -15 & -1 & +3 & -8 & -10 & -8 & +7 & +15 & +16 & +15 & +17 \\
\hline Heart diseases and dropsy & +11 & -31 & -17 & & & +3 & +5 & +14 & +12 & +13 & +16 & +28 \\
\hline Kidney diseases ..................... & +59 & +79 & +60 & +50 & +56 & +49 & +46 & +51 & +60 & +68 & +67 & +81 \\
\hline Cancer & +24 & & .... & .... & $\cdots$ & .... & +7 & +23 & +20 & +26 & +32 & +34 \\
\hline $\left.\begin{array}{c}\text { Childbirth and child- } \\
\text { bed ferer.............................. }\end{array}\right\}$ & -14 & & .. & & -17 & -11 & -13 & -12 & -23 & .... & $\cdots$ & .... \\
\hline Violence ................................. & -3 & -9 & -27 & -19 & -17 & -2 & +5 & +16 & +13 & +21 & +19 & +3 \\
\hline All other causes ....................... & -13 & -12 & -11 & -4 & -11 & -14 & -12 & -9 & -8 & -12 & -16 & -13 \\
\hline All causes ...................... & -9 & -11 & -25 & -22 & -24 & -22 & -17 & -7 & -2 & + & +3 & +1 \\
\hline
\end{tabular}

* Tables IIIA and B are placed first to allow the Tables $I_{\text {and }}$ II $_{A}$ and $B$ to be placed side and side, as in the case of Table IVA and B, for more convenient comparison. 
'Table IA.-England and W'ales. MaLes. Deaths from Various Causes at Eleven Groups of Ages. Averages of the Five Years 1876-80, compared with Averages of the Ten Years 1861-70.

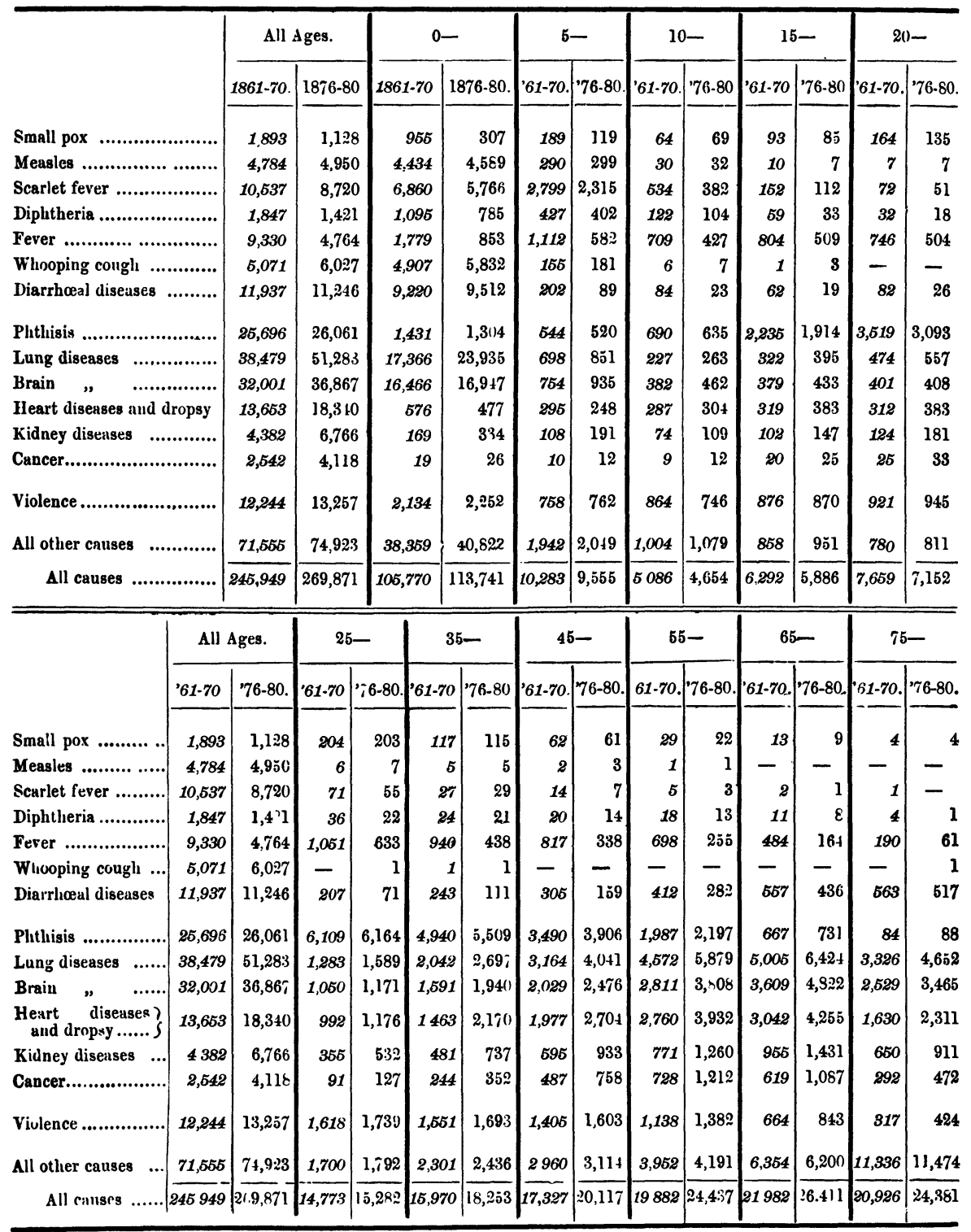




\section{4.] Death-Rate, in connection with the Causes of Death. 241}

TABle Iв.-England and Wales. Females. Deaths from Various Causes at Eleven Groups of Ages. Averages of the Five Years 1876-80, compared with Averages of the Ten Years 1861-70.

\begin{tabular}{|c|c|c|c|c|c|c|c|c|c|c|c|c|c|c|}
\hline & & \multicolumn{2}{|c|}{ All Ages. } & \multicolumn{3}{|c|}{$0-$} & \multicolumn{2}{|c|}{$5-$} & \multicolumn{2}{|c|}{$10-$} & \multicolumn{2}{|c|}{$15-$} & \multicolumn{2}{|c|}{$20-$} \\
\hline & & $1861-70$ & $1876-80$ & & $61-70.1$ & $1876-80$. & $61-70$. & $76-80$ & $61-70$ & $76-80$ & $61-70$. & $76-80$ & $6:-70$. & $\sim 6-80$. \\
\hline \multicolumn{2}{|c|}{ Small pox .......................... } & 1,586 & 930 & & 933 & 288 & 176 & 103 & 63 & 71 & 83 & 84 & 96 & 110 \\
\hline \multicolumn{2}{|c|}{ Measles ............................ } & 4,626 & $\mathbf{4 , 7 0 s}$ & & 4,219 & 4,286 & 321 & 344 & 36 & 31 & 13 & 11 & 10 & 8 \\
\hline \multirow{2}{*}{\multicolumn{2}{|c|}{$\begin{array}{l}\text { Scarlet fever .................. } \\
\text { Diphtheria }\end{array}$}} & 10,250 & 8,321 & & 6,486 & 5,436 & 2,710 & 2,183 & 601 & 374 & 162 & 106 & 107 & 73 \\
\hline & ......... & 2,099 & 1,628 & & 1,120 & 814 & 566 & 505 & 186 & 141 & 63 & 46 & 42 & 27 \\
\hline \multirow{2}{*}{\multicolumn{2}{|c|}{ Fever ......................... }} & 9,599 & 4,81 & & 1,824 & 835 & 1,221 & 654 & 897 & 536 & 943 & 569 & 730 & 428 \\
\hline & & 6,209 & 7,265 & & 5,961 & 7,000 & 230 & 244 & 12 & 12 & 3 & 2 & 1 & 2 \\
\hline \multicolumn{2}{|c|}{ Diarrhœal diseases ......... } & 11,083 & 10,15 & & 8,052 & $8, \approx 21$ & 203 & 104 & 70 & 28 & 62 & 22 & 102 & 40 \\
\hline \multicolumn{2}{|c|}{ 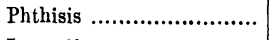 } & 27,247 & 25,030 & & 1,364 & 1,252 & 602 & 587 & 1,175 & 1,156 & 3,220 & 2,802 & 4,010 & 3,445 \\
\hline \multicolumn{2}{|c|}{$\begin{array}{l}\text { Lung diseases } \quad \text {.................. } \\
\text { Brain }\end{array}$} & 33,481 & 44,768 & & 14,510 & 19,744 & 695 & 850 & 247 & $2 \tau 2$ & 317 & 331 & 388 & 410 \\
\hline Brain $\quad, \quad \ldots . .$. & ........... & 27,574 & 32,12 & & 12,834 & 12,975 & 682 & 812 & 358 & 444 & 404 & 444 & 411 & $4: 9$ \\
\hline \multicolumn{2}{|c|}{ Heart diseases and dropsy } & 15,192 & 19,90 & & 503 & 410 & 265 & 265 & 322 & 386 & $3 \tilde{3}$ & 419 & 394 & $4 \pi 4$ \\
\hline \multicolumn{2}{|c|}{ Kidney diseases................ } & 1,994 & 3,75 & & 112 & 239 & 61 & 118 & 49 & 92 & 66 & 121 & 104 & 179 \\
\hline \multicolumn{2}{|c|}{ 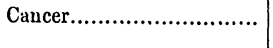 } & 5,740 & 8,37 & & 19 & 27 & 9 & 12 & 9 & 12 & 18 & 23 & 33 & 33 \\
\hline \multicolumn{2}{|c|}{ 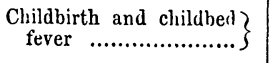 } & 3,525 & 3,56 & & - & - & - & - & - & 3 & 167 & 164 & 640 & 660 \\
\hline \multicolumn{2}{|c|}{ Violence ............................ } & 4,140 & 4,750 & & 1,667 & 1,804 & 398 & 350 & 151 & 147 & 152 & 151 & 120 & 136 \\
\hline \multirow{2}{*}{\multicolumn{2}{|c|}{$\begin{array}{r}\text { All other causes } \quad \ldots \ldots \ldots \ldots \\
\text { All causes } \quad . . \ldots \ldots \ldots \ldots . . . .\end{array}$}} & 69,156 & 71,15 & & 1,757 & $33,2+3$ & 1,661 & 1,761 & 865 & 996 & 829 & 872 & 858 & 833 \\
\hline & & 233,501 & 251,24 & & 1,361 & 96,574 & 9,800 & 8,902 & 5.042 & 4,701 & $6,8 \tilde{5}$ & 6,167 & 8,046 & $\tau, 292$ \\
\hline & \multicolumn{2}{|c|}{ All Ages. } & \multicolumn{2}{|c|}{$2 E-$} & \multicolumn{2}{|c|}{$35-$} & \multicolumn{2}{|c|}{$45-$} & & $5-$ & & $5-$ & & \\
\hline & '61-70. & $76-80$ & $61-70$. & $76-80$ & . $61-70$. & $76-80$ & $61-70$. & $76-80$ & $61-70$. & $76-80$ & $61-70$. & $\approx 6-80$ & $61 \cdot 70$ & $76-80$ \\
\hline ............. & 1,586 & 930 & 116 & 125 & 64 & 84 & 30 & 38 & 16 & 19 & 6 & 6 & 3 & 3 \\
\hline ................. & 4,626 & 4,709 & 15 & 15 & 7 & 7 & 3 & 3 & 1 & 2 & 1 & - & - & - \\
\hline er ........... & 10250 & 8,321 & 120 & 98 & 42 & 39 & 12 & 7 & 6 & 3 & 8 & 1 & 1 & - \\
\hline Diphtheria ............. & 2,099 & 1,628 & 47 & 33 & 28 & 26 & 21 & 12 & 14 & 12 & 8 & 8 & 3 & 2 \\
\hline .............. & 9,599 & 4,812 & 1,062 & 621 & 903 & 409 & 756 & 309 & 626 & 232 & 440 & 154 & 198 & 54 \\
\hline ng cough ... & 6,209 & $7,26 \vdots$ & 1 & 2 & - & 1 & - & 1 & - & 1 & - & 一 & - & - \\
\hline Diarrhœal diseases & 11,083 & 10,152 & 281 & $10 i$ & 292 & 122 & 290 & 146 & 416 & 282 & 616 & 476 & 701 & $6 C 5$ \\
\hline .............. & 27,247 & 25,030 & 7,248 & 6,409 & 4,987 & 4,824 & 2,746 & 2,641 & 1,348 & 1,353 & 473 & 477 & 74 & 85 \\
\hline Lung diseases $\ldots . .$. & 33,481 & 44,768 & 1,014 & 1,170 & 1,446 & 1,867 & 2,242 & 2,718 & 3,836 & 4,966 & 5,008 & 6,762 & 3,779 & 5,678 \\
\hline Brain $\quad, \quad \ldots .$. & 27,574 & 32,123 & 911 & 973 & 1,190 & 1,470 & 1,750 & 2,321 & 2,622 & 3,638 & 3,558 & 4,821 & 2,857 & 3,796 \\
\hline $\begin{array}{l}\text { s and } ? \\
\cdots \ldots . . .\end{array}$ & 15,192 & 19,907 & 1,044 & 1,270 & 1,523 & 2,005 & 2,096 & 2,702 & 3,109 & 4,202 & 3,602 & 4,904 & 1,980 & 2,869 \\
\hline Kidney diseases...... & 1,994 & 3,751 & 260 & 441 & 311 & 544 & 304 & 563 & 332 & 667 & 276 & 542 & 120 & 246 \\
\hline Cancer ................ & 5,740 & 8,375 & 270 & 333 & 860 & 1,226 & 1,482 & $2,06: 3$ & 1,502 & 2,270 & 1,073 & $1,6 \approx 3$ & $46 \tilde{5}$ & 704 \\
\hline $\left.\begin{array}{c}\text { Childbirth and } \\
\text { childbed fever }\end{array}\right\}$ & 3,525 & 3,567 & 1,525 & 1,532 & 1,136 & 1,155 & 58 & 51 & 一 & - & - & - & 一 & - \\
\hline Violence .................. & 4,140 & 4,750 & 224 & 275 & 245 & 326 & 273 & 356 & 262 & 380 & 274 & 385 & 374 & 439 \\
\hline All other causes $\quad .$. & 69,156 & 71,154 & 1,895 & 1,931 & 2,355 & 2,480 & 2,923 & 3,127 & 4,046 & 4,297 & 7121 & 7,024 & 14,841 & 14,589 \\
\hline All causes. & 233,501 & 251,242 & 16,033 & 5,335 & \begin{tabular}{l|l}
5 & 15,389
\end{tabular} & 16,585 & 14,986 & 17,058 & 18,136 &, 324 &, 458 & 27,233 & 25,396 &, 070 \\
\hline
\end{tabular}


Table IIA.-England and Wales. Males. Death-Rates per 100,000 Living at each Age, from Various Causes, at Eleven Groups of Ages. Averages of the Five Years 1876-80, compared with Averages of the Ten Years 1861-70.

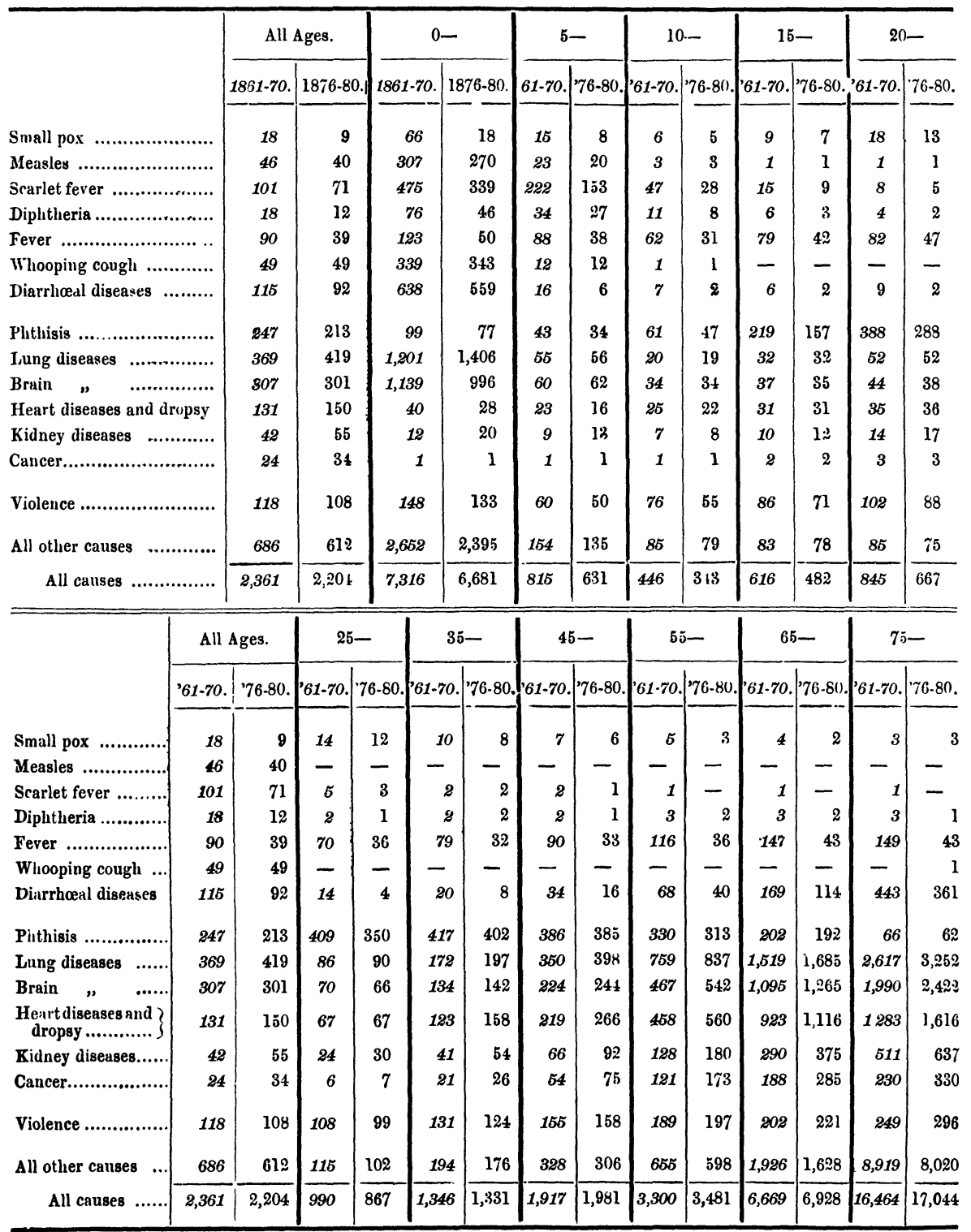


1884.] Death-Rate, in connection with the Causes of Death. 243

Table IIв.-England and Wales. Femalfs. Death-Rates per 100,000 Living at each Age, from Various Causes, at Eleven Groups of Ages. Averages of the Five Year's 1876-80, compared with Averages of the Ten Years 1861-70.

\begin{tabular}{|c|c|c|c|c|c|c|c|c|c|c|c|c|c|c|}
\hline & & \multicolumn{2}{|c|}{ All Ages. } & \multicolumn{3}{|c|}{$0-$} & \multicolumn{2}{|c|}{$5-$} & \multicolumn{2}{|c|}{$10-$} & \multicolumn{2}{|c|}{$15-$} & \multicolumn{2}{|c|}{$20-$} \\
\hline & & $1861-70$. & 187680 & & $61-70.1$ & 1876-80. & '61-70. & $76-80$ & 6170. & . $76-80$. & $61-70$. & $76-80$ & $61 \cdot 70$ & $76-80$ \\
\hline \multicolumn{2}{|c|}{ Small pox .............................. } & 15 & 7 & & 65 & 17 & 14 & 7 & 5 & 5 & 8 & 7 & 10 & 9 \\
\hline \multicolumn{2}{|c|}{ Measles …........................ } & 42 & 36 & & 293 & 251 & 25 & 23 & 3 & 2 & 1 & 1 & 1 & 1 \\
\hline \multicolumn{2}{|c|}{ Scarlet fever ........................ } & 93 & 64 & & 450 & 319 & 215 & $1+3$ & 53 & 28 & 16 & 9 & 11 & 6 \\
\hline \multicolumn{2}{|c|}{ 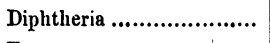 } & 19 & 13 & & 78 & 48 & 45 & 33 & 17 & 10 & 6 & 4 & 4 & 2 \\
\hline \multirow{2}{*}{\multicolumn{2}{|c|}{ 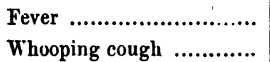 }} & 88 & 37 & & 127 & 49 & 97 & 44 & 80 & 40 & 91 & 47 & 72 & 36 \\
\hline & & 57 & 56 & & 414 & 410 & 18 & 16 & 1 & 1 & - & - & - & - \\
\hline \multicolumn{2}{|c|}{ Diarrhœal diseases ........... } & 101 & 79 & & 559 & 482 & 16 & 7 & 6 & 2 & 6 & 2 & 10 & 3 \\
\hline \multicolumn{2}{|c|}{ Phthisis ........................... } & 248 & 194 & & 95 & 73 & 48 & 39 & 105 & 86 & 311 & 227 & 397 & 293 \\
\hline \multirow{2}{*}{\multicolumn{2}{|c|}{$\begin{array}{l}\text { Lung diseases } \\
\text { Bryin } \quad, \quad \ldots \ldots \ldots \ldots \ldots . . . . . \\
\end{array}$}} & 305 & $3+7$ & & 1,007 & 1,157 & 55 & 56 & 22 & 20 & 31 & 27 & 38 & 35 \\
\hline & & 251 & 249 & & 891 & 761 & 54 & 53 & 32 & 33 & 39 & 36 & 41 & 37 \\
\hline \multicolumn{2}{|c|}{ Heart diseases and dropsy } & 139 & $15 t$ & & 35 & 24 & 21 & 17 & 29 & 29 & 34 & 34 & 39 & 40 \\
\hline \multirow{2}{*}{\multicolumn{2}{|c|}{$\begin{array}{l}\text { Kidney diseases } \\
\text { Cancer }\end{array}$}} & 18 & 29 & & 8 & 14 & 5 & 8 & 4 & 7 & 6 & 10 & 10 & 15 \\
\hline & & 52 & 65 & & 1 & 2 & 1 & 1 & 1 & 1 & $\boldsymbol{z}$ & 2 & 3 & 3 \\
\hline \multicolumn{2}{|c|}{$\left.\begin{array}{c}\text { Childbirth and childbed } \\
\text { fever }\end{array}\right\}$} & 32 & 28 & & - & - & - & - & - & - & 16 & 13 & 63 & 56 \\
\hline \multicolumn{2}{|c|}{ 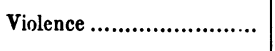 } & 38 & 37 & & 116 & 106 & 32 & 23 & 13 & 11 & 15 & 12 & 12 & 12 \\
\hline \multirow{2}{*}{\multicolumn{2}{|c|}{ All other causes }} & 630 & 551 & & 204 & 1,918 & 130 & 115 & 77 & 73 & 80 & 69 & 85 & 73 \\
\hline & & 2,128 & 1,916 & & ,343 & 5,661 & 776 & $58 \check{5}$ & 448 & 348 & 662 & 500 & 796 & 621 \\
\hline \multirow{3}{*}{ 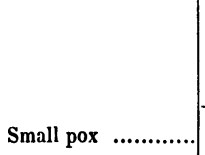 } & All & Ages. & 25 & & & $35-$ & & $5-$ & & 50 & & 5 & & $5-$ \\
\hline & 6170. & $76 \cdot 80$ & 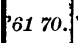 & i6-80. & 1. $61-70$. & $\because 6-80$ & $61-70$ & $76-80$ & 61.70. & . $76-80$. & $61-70$. & $76 i-80$ & $61-70$ & $76-80$ \\
\hline & 15 & 7 & 7 & 7 & 5 & 6 & 3 & 3 & 2 & 2 & 1 & 1 & 1 & \\
\hline Measles ….................. & 42 & 36 & 1 & 1 & 1 & 1 & - & - & - & - & - & - & - & - \\
\hline ....... & 93 & 64 & 7 & 5 & 3 & 3 & 1 & 1 & 1 & - & 1 & - & 1 & - \\
\hline ......... & 19 & 13 & 3 & 2 & 2 & 2 & 2 & 1 & 2 & 2 & 2 & 2 & 2 & \\
\hline ...... . & 88 & 37 & 64 & 32 & 71 & 28 & 79 & 28 & 96 & 30 & 115 & 34 & 120 & 29 \\
\hline g cough ... & 57 & 56 & - & - & - & - & - & - & - & - & - & - & - & - \\
\hline eases & 101 & 79 & 17 & 6 & 23 & 8 & 30 & $1:$ & 64 & 36 & 161 & 106 & 426 & 32 \\
\hline ......... & 248 & $19 \mathrm{t}$ & 438 & 334 & 390 & 327 & 285 & $32 \tau$ & 207 & 173 & 124 & 106 & 45 & 47 \\
\hline Lung diseases ....... & 305 & 317 & 61 & 61 & 113 & 126 & 233 & 244 & 586 & 634 & 1,311 & 1,305 & 2296 & 8,045 \\
\hline Brnin $\quad, \quad \ldots .$. & 251 & $2+9$ & 55 & 51 & 93 & 100 & 182 & 208 & 402 & 464 & 931 & 1,073 & 1,736 & 2,035 \\
\hline $\left.\begin{array}{r}\text { Heart diseases } \\
\text { and dropsy ........ }\end{array}\right\}$ & 139 & 154 & 63 & 66 & 119 & 136 & 218 & 243 & 476 & 536 & 943 & 1,091 & 1,203 & 1,538 \\
\hline es....... & 18 & 29 & 16 & 23 & 24 & 37 & 32 & 51 & 51 & 85 & 72 & 121 & 73 & 132 \\
\hline Cancer & 52 & 65 & 16 & 17 & 67 & 83 & 154 & 185 & 230 & 290 & 281 & 372 & 283 & 378 \\
\hline $\left.\begin{array}{l}\text { irth anc' } \\
\text { dbed ferer }\end{array}\right\}$ & 32 & 28 & 92 & 80 & 89 & 78 & 6 & 5 & - & - & - & - & - & - \\
\hline & 38 & 37 & 14 & 14 & 19 & 22 & 28 & 32 & 40 & 49 & 72 & 86 & 227 & 235 \\
\hline All other causes $\ldots$ & 630 & 551 & 115 & 101 & 184 & 166 & 303 & 280 & 620 & $5+8$ & 1,866 & 1,563 & 9,015 & 7,822 \\
\hline All causes ........ & & $1,9+6$ & 969 & 800 & 1203 & 1,123 & 1,556 & $|1,531|$ & 2,777 & $2,8+9$ & 5,880 & 6,060 & $\mid 15,428$ & 15,587 \\
\hline
\end{tabular}


TaBle IVA.-England and Wales. MaLes. Diminution or Increase of Deaths from Various Causes at Eleven Groups of Ages, Average of Five Years 1876 80, compared with Average of Ten Years 1861-70. Showing Annual Gain (-) or Loss (+) of Lives under each heading. Allowance is made for Increase of Population at each Group of Ages.

\begin{tabular}{|c|c|c|c|c|c|c|c|}
\hline & All Ages. & 0 - & 5 - & & $10-$ & $15-$ & $20-$ \\
\hline Small pox & $-1,106$ & $-\quad 820$ & -10 & - & & $-\quad 26$ & $-\quad 59$ \\
\hline Measles ....................... & -691 & $-\quad 632$ & -4 & - & 4 & & -1 \\
\hline Scarlet fever ............. & $-3,758$ & $-2,312$ & $-1,04$ & & 253 & & \\
\hline 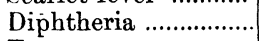 & $-\quad 766$ & $-\quad 504$ & -11 & & 41 & $-\quad 38$ & $\begin{array}{l}-\quad 20 \\
-\quad 1\end{array}$ \\
\hline 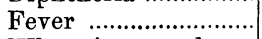 & $-6,188$ & $-1,242$ & -75 & & 417 & -453 & -379 \\
\hline Whooping cough ... & $+\quad 51$ & $+\quad 54$ & $-1-$ & & & $\ldots$ & $\cdots$ \\
\hline Diarrhøal diseases... & $-2, \% 52$ & $-1,345$ & -15 & - & 77 & $-\quad 55$ & -71 \\
\hline Phthisis . & $-3,366$ & $-\quad 381$ & -13 & & 186 & -761 & $-1,071$ \\
\hline Lung diseases............. & $+6,490$ & $+3,486$ & +1 & - & & $+\quad 10$ & \\
\hline Brain , $" \quad \ldots \ldots . . .$. & -465 & $-2,413$ & +3 & + & 7 & -21 & $-\quad 67$ \\
\hline $\left.\begin{array}{r}\text { Heart diseases and } \\
\text { dropsy ............................ }\end{array}\right\}$ & $+2,565$ & $-\quad 201$ & -10 & & 37 & $\cdots$ & +14 \\
\hline Kidney diseases ......... & $+1,702$ & 135 & +6 & + & 21 & $+\quad 25$ & 34 \\
\hline 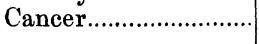 & $+1,187$ & + & $\ldots$ & & 1 & +1 & + \\
\hline Violence .... & $-1,063$ & $-\quad 261$ & -14 & & 282 & -178 & -145 \\
\hline All other causes ....... & $-8,425$ & $-4,346$ & -28 & & 116 & -74 & -112 \\
\hline \multirow[t]{2}{*}{ All causes } & $-17,185$ & $-10,808$ & $-2,78$ & & 1,398 & $-1,645$ & $-1,912$ \\
\hline & All Ages. & $25-$ & $35-$ & $45-$ & $5 \tilde{-}-$ & $65-$ & $75-$ \\
\hline & $-1,106$ & $-\quad 38$ & -20 & - & 12 & & \\
\hline Measle & -691 & $\ldots$ & -1 & + & & $\ldots$ & $\ldots$ \\
\hline Scarlet fever & $-3,758$ & $-\quad 29$ & -2 & - & - & -1 & \\
\hline Diphtheria ...................... & $-\quad 766$ & -21 & -7 & -8 & -8 & -5 & -4 \\
\hline Fever & $-6,188$ & -609 & -649 & -580 & -558 & $\mid-3 \div 6$ & -153 \\
\hline Whooping cough .... & $+\quad 51$ & +1 & & & $\ldots$. & $\ldots$ & +1 \\
\hline Diarrhœal diseases.... & $-2,752$ & -174 & -170 & -184 & -198 & -208 & -117 \\
\hline & $-3,966$ & $-1,053$ & -202 & -14 & -118 & $-\quad 40$ & \\
\hline Lung diseases............. & $+6,490$ & +73 & +336 & +487 & +552 & +635 & +909 \\
\hline Brain $", \quad \ldots \ldots \ldots$ & $-\quad 465$ & $-\quad 69$ & +101 & +197 & +533 & +648 & +619 \\
\hline $\left.\begin{array}{r}H \text { eart diseases and } \\
\text { dropsy ..................... }\end{array}\right\}$ & $+2,565$ & +4 & +479 & +483 & +716 & +737 & +476 \\
\hline Kidney diseases ......... & $+1,702$ & +113 & +181 & +265 & +362 & +326 & +179 \\
\hline 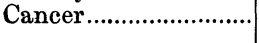 & $+1,187$ & +19 & +70 & +211 & +364 & +371 & +143 \\
\hline Violence ........................... & $-1,063$ & -172 & -100 & +25 & $+\quad 56$ & +75 & +67 \\
\hline All other causes......... & $-8,425$ & -216 & -224 & -212 & $-\quad 414$ & $-1,149$ & $-1,282$ \\
\hline All causes ........... & $-17,185$ & $-2,171 \mid$ & -208 & +653 & $+1,272$ & +987 & +829 \\
\hline
\end{tabular}


1884.] Death-Rate, in connection with the Causes of Death.

'Table IVB.-England and Wales. Females. Diminution or Increase of Deaths from Various Causes at Eleven Groups of Ages. Average of Five Years 1876-80, compared with Average of Ten Years 1861-70. Showing Annual Gain (-) or Loss (+) of Lives under each headir.g. Allowance is nade for Increase of Population at each Group of Ages.

\begin{tabular}{|c|c|c|c|c|c|c|c|}
\hline & All dges. & $0-$ & $5-$ & & 0 & $15-$ & $20-$ \\
\hline Small pox ... & -945 & $-\quad 817$ & -109 & - & 5 & $-\quad 15$ & \\
\hline Measles ....................... & $-\quad 77 \%$ & -711 & $-\quad 43$ & & 12 & - & - \\
\hline Scarlet fever ................ & $-3,879$ & $-2,247$ & $-1,084$ & & 348 & & 51 \\
\hline Diphtheria ...................... & -870 & $-\quad 513$ & -177 & - & 82 & -30 & $-\quad 22$ \\
\hline Fever ............................ & $-6,510$ & $-1,326$ & -808 & & 541 & -554 & -4211 \\
\hline Whooping cough .... & -93 & & $-\quad 33$ & - & 2 & -2 & $+\quad 1$ \\
\hline Diarrhœal diseases... & $-2,919$ & $-1,317$ & -141 & - & 56 & $-\quad 52$ & -79 \\
\hline Phthisis ....... & $-6,806$ & $-\quad 364$ & -139 & & 255 & $-1,034$ & $-1,216$ \\
\hline Lung diseases.................. & $+5,404$ & $+2,557$ & $+\quad 12$ & - & 25 & $-\quad 47$ & -41 \\
\hline$" \quad \ldots \ldots \ldots$ & -313 & $-2,227$ & $-\quad 10$ & + & & $-\quad 37$ & - \\
\hline $\left.\begin{array}{r}\text { Heart diseases and } \\
\text { dropsy .............................. }\end{array}\right\}$ & $+2,121$ & $-\quad 186$ & $-\quad 54$ & - & 1 & - & +16 \\
\hline Kidney diseases ....... & $+1,417$ & 106 & + & + & 33 & 42 & + \\
\hline 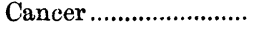 & $+1,661$ & + & + & + & & + & - \\
\hline $\left.\begin{array}{r}\text { Childbirth and } \\
\text { childbed fever.... }\end{array}\right\}$ & -523 & $\cdots$. & .... & + & & $-\quad 35$ & -84 \\
\hline 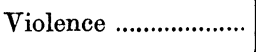 & $-12_{4}$ & $-\quad 171$ & -130 & - & 34 & $-\quad 30$ & - \\
\hline All other causes........ & - 9,837 & $-4,372$ & -241 & - & 42 & -115 & -159 \\
\hline All causes ......... & $-22,993$ & $-11,645$ & $-2,912$ & -1 &, 352 & $-1,999$ & $-2,060$ \\
\hline & All Ages. & $25-$ & $35-$ & $45-$ & $55-$ & $65-$ & $75-$ \\
\hline Small pox & -945 & 9 & & 3 & & & $\ldots$. \\
\hline $\mathbf{M}$ & $-\quad 77 \%$ & - & & & + & - & \\
\hline carlet fever ................ & $-3,879$ & & & -7. & - & - & \\
\hline Diphtheria ....................... & $-8 \% 0$ & & & -12 & -5 & & \\
\hline 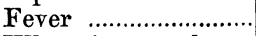 & $-6,510$ & -609 & -634 & -565 & -519 & -364 & -170 \\
\hline Whooping cough .... & -93 & & & +1 & +1 & $\ldots$. & $\ldots$ \\
\hline Diarrhœal diseases.... & $-2,919$ & -218 & -215 & -189 & -217 & -246 & $-1 \diamond 9$ \\
\hline Phthisis & $-6,806$ & $-1,983$ & -937 & -534 & -265 & -80 & \\
\hline Lung & $+5,404$ & & +197 & +126 & +362 & +870 & $+1,397$ \\
\hline Brain $\quad ", \quad \ldots \ldots \ldots$ & $-\quad 313$ & 82 & +95 & +298 & +4.91 & +635 & +559 \\
\hline 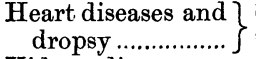 & $+2,121$ & $+\quad 61$ & +246 & +279 & +4.71 & +664 & +626 \\
\hline Kidney diseases .......... & $+1,417$ & +141 & +185 & +212 & +269 & +217 & +110 \\
\hline 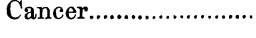 & $+1,661$ & $+\quad 20$ & +233 & +350 & +467 & +411 & +177 \\
\hline $\left.\begin{array}{r}\text { Childbirth and } \\
\text { childbed fever.... }\end{array}\right\}$ & -523 & -234 & -157 & -16 & $\cdots$ & $\cdots$ & .... \\
\hline 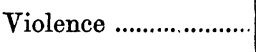 & -124 & +16 & $+\quad 44$ & +49 & +66 & $+\quad 63$ & +15 \\
\hline All other causes.......... & $-9,837$ & -264 & -243 & -254 & -561 & $-1,357$ & $-2,229$ \\
\hline All causes ....... & $-22,993$ & $-3,228$ & $-1,192$ & -268 & +557 & +809 & +297 \\
\hline
\end{tabular}


TABLE VA.-Englanä and Wales. Males. Deaths from Various Causes during Childhood and Youth, Working-Life, and Old Age. Averages of the Five Years 1876-80, compared with Averages of the Ten Yeurs 1861-70.

\begin{tabular}{|c|c|c|c|c|c|c|}
\hline \multirow[t]{2}{*}{ Ages .................. } & \multicolumn{2}{|c|}{$0-20}$. & \multicolumn{2}{|c|}{$20-65$} & \multicolumn{2}{|c|}{$65-$} \\
\hline & $1861-70$ & $1876-80$ & $1861-70$. & $1876-80$ & $1861-70$ & $1876-80$ \\
\hline Small pox .... & 1,302 & 578 & 574 & 535 & 16 & 13 \\
\hline 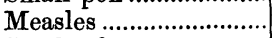 & 4,764 & 4,926 & 20 & 23 & - & - \\
\hline Scarlet fever .................. & 10,345 & 8,575 & 189 & 145 & 3 & 1 \\
\hline Diphtheria ....................... & 1,702 & 1,323 & 130 & 89 & 15 & 9 \\
\hline 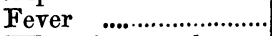 & 4,404 & 2,371 & 4,252 & 2,168 & 674 & 22,4 \\
\hline Whooping cough ........ & 5,068 & 6,022 & 3 & 3 & - & 1 \\
\hline Diarrhcal diseases ... & 9,568 & 9,644 & 1,248 & 649 & 1,121 & 953 \\
\hline 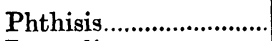 & 4,900 & 4,373 & 20,045 & 20,868 & 751 & 820 \\
\hline Lung diseases .................. & 18,613 & 25,444 & 11,535 & 14,764 & 8,332 & 11,076 \\
\hline Brain $\quad " \quad \ldots . . . . . . .$. & 17,981 & 18,777 & 7,882 & 9,804 & 6,138 & 8,287 \\
\hline Heart diseases, \&c. .... & 1,477 & 1,412 & 7,505 & 10,365 & 4,672 & 6,565 \\
\hline Kidney diseases ......... & 452 & 781 & 2,325 & 3,643 & 1,605 & 2,341 \\
\hline 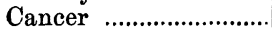 & 58 & 76 & 1,574 & 2,483 & 910 & 1,559 \\
\hline Violence & 4,631 & 4,629 & 6,632 & 7,361 & 981 & $1,26 t$ \\
\hline All other causes ......... & 42,165 & 44,905 & 11,697 & 12,344 & 17,690 & 17,676 \\
\hline All causes .............. & 127,430 & 133,836 & 75,611 & 85,242 & 42,908 & 50,792 \\
\hline
\end{tabular}

TABle VB.-England and Wales. Females. Deaths from Various Causes during Childhood and Youth, Working-Life, and old Age. Averages of the $F^{\prime}$ ive Years 1876-80, compared with Averages of the Ten Years $1861-70$.

\begin{tabular}{|c|c|c|c|c|c|c|}
\hline \multirow[t]{2}{*}{ Ages ................... } & \multicolumn{2}{|c|}{$0-20}$. & \multicolumn{2}{|c|}{$20-65}$. & \multicolumn{2}{|c|}{65 - } \\
\hline & $1861-70$. & $1876 \cdot 80$ & $1861-70$. & $1876-80$ & $1861-\% 0$ & $1876 \cdot 80$ \\
\hline 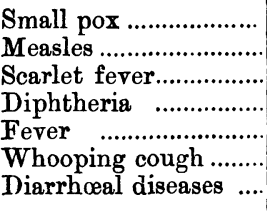 & $\begin{array}{l}1,254 \\
4,589 \\
9,960 \\
1,935 \\
4,884 \\
6,206 \\
8,387\end{array}$ & $\begin{array}{r}546 \\
4,672 \\
8,099 \\
1,506 \\
2,604 \\
7,258 \\
8,375\end{array}$ & $\begin{array}{r}323 \\
36 \\
287 \\
152 \\
4,0 \% 6 \\
3 \\
1,380\end{array}$ & $\begin{array}{r}376 \\
36 \\
220 \\
110 \\
1,999 \\
7 \\
697\end{array}$ & $\begin{array}{r}9 \\
1 \\
3 \\
11 \\
638 \\
- \\
1,317\end{array}$ & $\begin{array}{r}9 \\
1 \\
1 \\
10 \\
208 \\
-\quad \\
1,081\end{array}$ \\
\hline 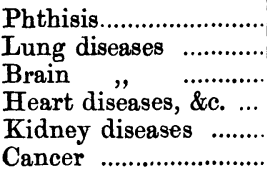 & $\begin{array}{r}6,361 \\
15,769 \\
14,277 \\
1,4,3 \\
288 \\
54\end{array}$ & $\begin{array}{r}5,797 \\
21,197 \\
14,675 \\
\mathbf{1 , 4 8 0} \\
\mathbf{5 7 0} \\
\mathbf{7 4}\end{array}$ & $\begin{array}{r}20,339 \\
8,926 \\
6,882 \\
8,167 \\
1,310 \\
4,147\end{array}$ & $\begin{array}{r}18,672 \\
11,131 \\
8,831 \\
10,653 \\
2,394 \\
5,925\end{array}$ & $\begin{array}{r}547 \\
8,787 \\
6,415 \\
5,582 \\
396 \\
1,538\end{array}$ & $\begin{array}{r}562 \\
12,440 \\
8,617 \\
7,773 \\
788 \\
2,377\end{array}$ \\
\hline Childbirth, \&c................ & 167 & 167 & 3,358 & 3,398 & - & 一 \\
\hline Viclence & 2,368 & 2,452 & 1,124 & 1,473 & 649 & 824 \\
\hline All other causes .......... & 35,115 & 36,872 & 12,081 & 12,671 & 21,962 & 21,613 \\
\hline All causes ............. & 113,058 & 116,344 & 72,590 & 78,594 & 47,853 & 56,303 \\
\hline
\end{tabular}


1884.] Death-Rate, in connection with the Causes of Death.

Table VIA.-England and Wales. Males. Death-Rates per 100,000 Living at each Age from Various Causes during Childhood and Youth, Working-Life, and Old Age. Averages of the Five Years 1876-80, compared with Averages of the Ten Years 1861-70.

\begin{tabular}{|c|c|c|c|c|c|c|}
\hline \multirow[t]{2}{*}{ Ages ..................... } & \multicolumn{2}{|c|}{$0-20$} & \multicolumn{2}{|c|}{$20-65$} & \multicolumn{2}{|c|}{$65-$} \\
\hline & $1861-\tau 0$. & $1876-80$ & $1861-\% 0$. & $1876-80$ & $1861-\% 0$ & 187680. \\
\hline Small pox …........................ & 27 & 10 & 11 & 9 & 4 & 3 \\
\hline 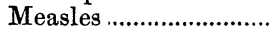 & 98 & 85 & - & - & - & - \\
\hline Scarlet fever ...................... & 213 & 148 & 4 & 3 & - & - \\
\hline Diphtheria ...................... & 35 & 23 & 3 & 2 & 3 & 2 \\
\hline Fever ........ & 90 & 41 & 84 & 37 & 148 & 43 \\
\hline Whooping cough ....... & 104 & 104 & - & - & - & - \\
\hline Diurrhœal diseases .... & 197 & 166 & 25 & 11 & 245 & 182 \\
\hline 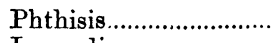 & 101 & 76 & 394 & 352 & 164 & 156 \\
\hline Lung diseases ............... & 382 & 439 & 227 & 249 & 1,824 & 2,113 \\
\hline Brain $\quad, \quad \ldots \ldots \ldots \ldots . . . .$. & 369 & 324 & 155 & 166 & 1,344 & $1, \tilde{081}$ \\
\hline Heart diseases, \&c. .... & 30 & 24 & 147 & 175 & 1,023 & 1,252 \\
\hline Kidney diseases ......... & 9 & 14 & 46 & 62 & 351 & 447 \\
\hline Cancer .................................. & 1 & 1 & 31 & 42 & 199 & 297 \\
\hline Violence & 95 & 80 & 130 & 124 & 215 & 242 \\
\hline All other causes .......... & 866 & 774 & 228 & 207 & 3,875 & 3,370 \\
\hline All causes ................ & 2,617 & 2,309 & $1,8.5$ & 1,439 & 9,395 & 9,688 \\
\hline
\end{tabular}

Table VIb.-England and Wales. Females. Death-Rates per 100,000 Living at each Age from Various Causes during Childhood and Youth, Working-Life, and Old Age. Averages of the Five Years 1876-80, compared with Averages of the Ten Yeurs 1861-70.

\begin{tabular}{|c|c|c|c|c|c|c|}
\hline \multirow[t]{2}{*}{ Ages .................... } & \multirow{2}{*}{\multicolumn{2}{|c|}{$\frac{0-20 .}{1 S 61-70 . ' 1876-80}$}} & \multicolumn{2}{|c|}{$20-65$} & \multicolumn{2}{|c|}{65 - } \\
\hline & & & $1861-70$ & $1876-80$ & $1861-\% 0$ & $1876-80$ \\
\hline 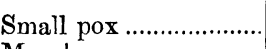 & 26 & 9 & 6 & 6 & 2 & 2 \\
\hline 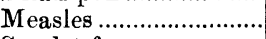 & 94 & 80 & 1 & 1 & - & - \\
\hline Scarlet ferer .................. & 205 & 139 & 5 & 3 & - & - \\
\hline Diphtheria & 40 & 26 & 3 & 2 & 2 & 2 \\
\hline Fever …….................. & 100 & 45 & 73 & 31 & 117 & 33 \\
\hline Whooping cough ........ & 128 & 125 & - & - & - & $\overline{-}$ \\
\hline Diarrhœal diseases .... & 173 & 144 & 25 & 11 & 241 & 170 \\
\hline 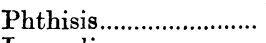 & 131 & 100 & 366 & 289 & 100 & 88 \\
\hline Lung diseases ............. & 324 & 365 & 161 & 172 & 1,608 & 1,956 \\
\hline Brain $\quad, \quad$............. & 294 & 253 & 124 & 137 & 1,174 & 1,355 \\
\hline Heart diseases, \&c. ... & 30 & 26 & 147 & 165 & 1,021 & 1,222 \\
\hline Kidney diseases ........ & 6 & 10 & 24 & 37 & 73 & 124 \\
\hline 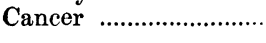 & 1 & 1 & 75 & 92 & 281 & $3 ; 4$ \\
\hline Childbirth, \&c............. & 3 & 3 & 60 & 53 & - & - \\
\hline Violence & 49 & 42 & 20 & 23 & 119 & 130 \\
\hline All other causes .......... & $\gamma^{21}$ & 634 & 215 & 193 & 4,017 & 3,398 \\
\hline All causes .............. & 2,325 & 2,002 & 1,305 & 1,215 & 8,755 & 8,854 \\
\hline
\end{tabular}


248 Longstaff-On the Decline in the English Death-Rate. [June,

Table VII.-England and Wales. Percentage Fall or Rise of the DeathRates from Various Causes at Three Groups of Ages representing Childhood and Youth, Working-Life, and Old Age respectively. Average of the Five Years 1876-80, compared with Average of the Ten Year's 1861-70.

\begin{tabular}{|c|c|c|c|c|c|c|}
\hline \multirow[b]{2}{*}{ Ages ........................ } & \multicolumn{3}{|c|}{ Males. } & \multicolumn{3}{|c|}{ Females. } \\
\hline & $0-20$. & $20-65$. & $65-$ & $0-20$ & $20-65$ & $65-$ \\
\hline 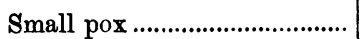 & -63 & -20 & $\ldots$. & -65 & $\ldots$. & $\ldots$ \\
\hline 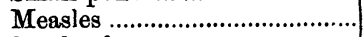 & -13 & $\ldots$ & $\ldots$. & -15 & $\ldots$ & $\ldots$. \\
\hline 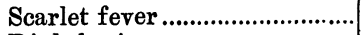 & -30 & -32 & .... & -32 & -40 & $\ldots$. \\
\hline Diphtheria .......................... & -35 & -42 & $\ldots$ & -35 & -33 & $\ldots$ \\
\hline Fever & -55 & -56 & -71 & -55 & -58 & -72 \\
\hline 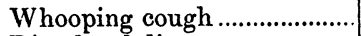 & $\ldots$ & $\ldots$ & $\ldots$ & -2 & .... & $\ldots$ \\
\hline Diarrhœal diseases ............... & -15 & -55 & -26 & -17 & -56 & -29 \\
\hline Phthisis & -25 & -11 & -5 & -24 & -21 & -12 \\
\hline Lung diseases .......................... & +15 & +10 & +16 & +13 & +7 & +22 \\
\hline Brain $\quad, \quad$........................... & -12 & +7 & +18 & -14 & +10 & +15 \\
\hline Heart diseases and dropsy .... & -19 & +19 & +22 & -13 & +12 & +20 \\
\hline Kidney diseases ....................... & +45 & +35 & +27 & +67 & +54 & +70 \\
\hline 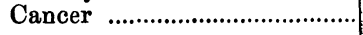 & $\cdots$ & +36 & +49 & $\cdots$ & +23 & +33 \\
\hline Childbirth and childbed fever & $\cdots$ & $\cdots$ & $\cdots$ & $\cdots$ & -12 & $\cdots$ \\
\hline 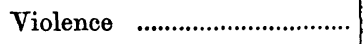 & -16 & -5 & +13 & -14 & +15 & +9 \\
\hline All other causes & -11 & -9 & -13 & -12 & -10 & -15 \\
\hline All causes........................ & -12 & -3 & +3 & -14 & -7 & +1 \\
\hline
\end{tabular}

TABLE VIII.-England and Wales. Diminution or Increase of Deaths from Various Causes at Three Groups of Ages. Average of Five Years 1876-81), compared with Average of Ten Years 1861-70. Showing Annual Gain (-) or Loss (+) of Lives during Childhood and Youth, Working-Life, and Old Age respectively, after Allowance is made for Increase of Population at each Age.

\begin{tabular}{|c|c|c|c|c|c|c|}
\hline \multirow[b]{2}{*}{ Ages.......................... } & \multicolumn{3}{|c|}{ Males. } & \multicolumn{3}{|c|}{ Females. } \\
\hline & $0-20$. & $20-65$. & $65-$ & $0-20$ & $20-65$. & $65-70$. \\
\hline Small pox & -961 & -138 & & 946 & + & - \\
\hline 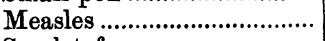 & $-\quad 690$ & $-\quad 1$ & & 770 & -6 & - \\
\hline 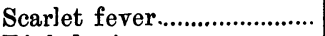 & $-3,679$ & & - & $-3,766$ & -113 & \\
\hline Diphtheria ............................... & -693 & & & $-\quad 802$ & -66 & $-\quad 2$ \\
\hline Fever & $-2,864$ & $-2,775$ & -549 & $-3,229$ & $-2,747$ & \\
\hline Whooping cough .................. & $+\quad 49$ & & & & & \\
\hline Diarrhœal diseases ........... & $-1,630$ & -797 & -325 & $-1,566$ & -918 & --435 \\
\hline 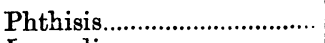 & $-1,461$ & $-2,458$ & $-\quad 47$ & $-1,792$ & $-4,935$ & $-\quad 79$ \\
\hline Lung diseaseg . ........................ & $+3,502$ & $+1,444$ & $+1,544$ & $+2,497$ & +640 & $+2,267$ \\
\hline 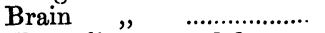 & $-2,427$ & +695 & $+1,267$ & $-2,260$ & +753 & $+1,194$ \\
\hline Heart diseases and dropsy. & -344 & $+1,696$ & $+1,213$ & 242 & $+1,073$ & $+1,290$ \\
\hline Kidney diseases .................... & $24: 2$ & +955 & +505 & 225 & +865 & +327 \\
\hline 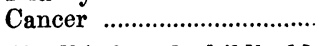 & & +667 & +514 & 8 & $+1,065$ & +588 \\
\hline $\left.\begin{array}{r}\text { Childbirth and childbed } \\
\text { fever }\end{array}\right\}$ & $\cdots$ & ... & & 32 & -491 & .... \\
\hline 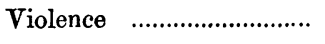 & $-\quad 869$ & -336 & +142 & $-\quad 365$ & +163 & +78 \\
\hline All other causes .................... & $-4,816$ & $-1,178$ & $-2,431$ & $-4,770$ & $-1,481$ & $-3,586$ \\
\hline All causes ...................... & $-16,635$ & $-2,366$ & $+1,816$ & $-17,908$ & $-6,191$ & $+1,106$ \\
\hline
\end{tabular}


TABLE IX.-England and Wales. Death-Rates of Females, compared to Death-Rates of Males taken as 1oo, from Various Causes, during Childhood and Youth, Working-Life, and Old Age. Average of Five Years 1876-80.

\begin{tabular}{|c|c|c|c|}
\hline & $0-20$. & $20-65$. & 65 -. \\
\hline Small pox & 90 & 67 & 67 \\
\hline 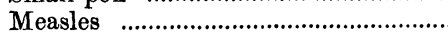 & 94 & - & - \\
\hline 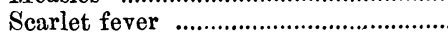 & $9 \mathrm{k}$ & 100 & - \\
\hline Diphtheria & 113 & 100 & 100 \\
\hline 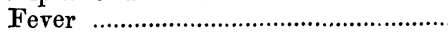 & 110 & 81 & 77 \\
\hline 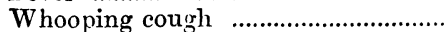 & 120 & - & - \\
\hline 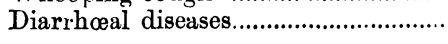 & 87 & 100 & 93 \\
\hline Phthisis & 132 & 82 & 56 \\
\hline 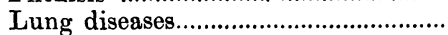 & 83 & 69 & 93 \\
\hline 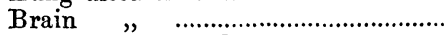 & 78 & 83 & 86 \\
\hline 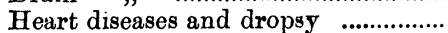 & 108 & 94 & 98 \\
\hline 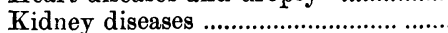 & 71 & 61 & 28 \\
\hline Cancer & 100 & 219 & 126 \\
\hline Childbirth an 1 childbed fever ............. & - & - & - \\
\hline 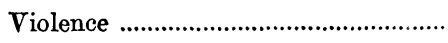 & 53 & 19 & 54 \\
\hline 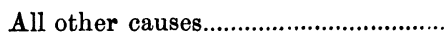 & 82 & 93 & 101 \\
\hline 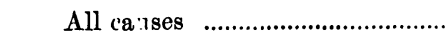 & 87 & 84 & 91 \\
\hline
\end{tabular}

\section{Discussion on Dr. Longstaff's Paper.}

Mr. A. H. BAILey said he was very grateful to Dr. Longstaff for the pains he had taken to elucidate this difficult subject, but while he implicitly trusted the accuracy of the tables, he somewhat distrusted the materials from which they had been deduced. When Mr. Humphreys read his paper last session, he (Mr. Bailey) said it was premature to jump to the conclusion that the mortality of the country had decreased, merely because the results of fire, or six, or seven years, when there had been no epidemics, had proved favourable, and that though it clearly appeared that the mortality of females has improved, the rate of mortality of males was precisely the same as forty years ago. So many mistakes had been made in past times about improvement in human mortality that it was better to be a little cautious, and the same remark applied to the returns of ages. It should be remembered that the ages of the living were given by the living themselves, and yet the compilers of the census fairly and justly said that the figures must be taken with caution, and only as approximations. On the other hand the 
ages of death were given by the relatives and friends of the deceased persons. For instance, the ages of the deaths in workhouses must be loosely returned, and in many cases be mere guesses. It therefore seemed to him that it was scarcely worth while to deduce these elaborate results from such insufficient material. There was also considerable difficulty about the causes of death. Comparing the returns in the early registrar-general's reports with the later, it appeared to him that the same diseases were returned under different headings. Take for example phthisis, which was in this country the most formidable cause of death. In the early reports it was grouped under "Diseases of the respiratory organs." Later on it appeared as a tuhercular disease, classed with scrofula; while at present it figured among constitutional diseases, such as gout; and yet the popular idea in the country was that it was a disease of the lungs. He hoped that it would not be thought he was not most gratefal to Dr. Longstaff for the pains he had taken to elucidate a difficult subject, because he said much cantion was needed with regard to the materials from which the results were derived.

Mr. N. A. Humphreys said, with regard to the remarks of the last speaker, there was a great temptation to criticise such papers hostilely on account of the imperfections of the materials from which the statistics were constructed; but if statisticians were to wait until the materials they had to use were perfect, and they could deal with veritable facts, they would have to wait a very long time before doing any work at all. Dr. Longstaff had shown a great deal of caution and skill in avoiding the greatest difficulties in dealing with a subject of this kind. One of the most valuable results of the paper was that it showed that the entire decrease of the death-rate had taken place in two classes of diseases, zymotic diseases and phthisis. This was a very encouraging fact for those who took an interest in sanitary matters, becanse those were the very diseuses which had most attracted the efforts of sanitarians. The tables showed that the whole decrease had occurred in the principal zymotic diseases and phthisis, whereas the mortality from all other diseases had remained practically stationary. The decline of fever was a great triumph of sanitation. Measles and whooping cough, which showed no decline, had not yet been attacked in the same way, and there had scarcely been any attempt to isolate them. One great point that Dr. Longstaff made was showing that the general impression of the interchange between lung diseases and phthisis in the death registry was not tenable. At those very ages showing the greatest decrease in fatal phthisis, lung diseases had not increased. In one part of the paper Dr. Longstaff asked what effect these changes in the death-rate had made in the constitution of the population. Those changes had only been going on a few years, and therefore it could hardly be expected that there would be much change in the constitution of the population as yet; but comparing 1871 with 1881 , there were some considerable changes, and doubtless hereafter they would be greater. Still the change in the last ten years meant a reduction of 5,000 
deaths in England and Wales. But this reduction in its effect on the rate of mortality was not relatively of great importance, because it would only make a difference of one-fifth of one per thousand in the annual death-rate. In his own recent paper he had pointed out that there had been a slight but decided increase in the mortality at later ages. People had asked what was the use of a decline of mortality among young people if elderly people died faster; but the increase in the later ages appeared to have ceased, and in 1881-83 there was a decrease at each group of ages, including those of elderly persons. Dr. Longstaff had suggested that for the help of medical officers of health and others, the registrar-general should publish a table of factors which would enable people to correct the various returns in different towns, so as to make the recorded death-rates strictly comparable. This suggestion had been to some extent anticipated; and a table of such factors would appear in the registrar-general's summary for the twenty-eight large towns of England and Wales in 1883, now in the press. No one present could speak more confidently than he could as to the immense amount of work involved in Dr. Longstaff's calculations, and as to the great difficulties he had had to contend with in consequence of the imperfections of the materials with which he had to deal, imperfections of which the registrar-general's office were thoroughly aware.

Sir R. W. RAwson said he could not approach this question from a medical point of view, or from that of an actuary, but from a statist's point of view. In the objections raised to the paper by Mr. Bailey, the uncertainty in the record of ages prevailed over the whole period, and the experience of statists showed that errors of that nature balanced one another. It was therefore fair to compare the ages in the first ten years with those in the latter period of five years, more particularly when the observations covered such a narrow period as fifteen years, during which no material change had been made in the system or the practice of observation. Although he thanked Mr. Bailey for suggesting caution in receiving the conclusions presented in the paper, he thought there was not much ground for his objection to them. He heartily joined with Mr. Humphreys in thanking Dr. Longstaff for his very valuable paper, which not only showed interesting results drawn from official and most carefully observed documents, but also suggested observations for the future which might lead to very important consequences, and encourage those who were interested in improving the sanitary condition of the population.

Mr. E. LuNd (Manchester) said that in questions of statistics there was an abstract view in which we endeavoured to secure almost mathematical accuracy; but the data to be dealt with were so variable, that only a distant approximation to such a result could be obtained. There was also a thoroughly practical view, the object of which was to see what could be done with knowledge thus imperfectly obtained. He had been much strack with one or 
two practical remarks in the paper. One had reference to whether quinquennial or decennial periods for observation were the best; and another was that the period of life from 17 to 35 was that in which a member of society was most valuable to it. It had often occurred to him, looking at the matter from a practical point of view, that if the death-rate of towns and counties could be drawn out at so much per thousand or ten thousand, and this again analysed for quinquennial periods, those who had not the opportunity of going into the matter scientifically would have forced upon them the question of the cause of death at those different periods of life. In the factory districts that problem had to be dealt with. There was there a very high death-rate, but if the deaths under 20 , or 15 , or 10 were eliminated, the rate for the middle period of life was not so high as might be anticipated, cases of fever being exciuded. The cause of this was apparent. The parents had to go to their work and the children were neglected. In addition to this there was the great problem of milk supply and dietary for children. With regard to the recent gain at one end of the scale and loss at the other, although it was but an approximation, it taught a very good lesson, and showed that by a more accurate record of deaths, and more accurate nomenclature of diseases, information might be ohtained which would become more and more valuable and applicable to the great question of sanitary reform. In the north of England an attempt had been made to have a record not only of cause of death but also of disease, so that from a sanitary point of view it might be known what was going on in the population, not by the final result, but by the progress of a few classes of diseases, particularly the zymotic. They were however met here with the same objection as to errors of diagnosis or imperfect information. He was sure that in addressing the members of the Statistical Society he need not refer to that grand principle, that by taking large groups of facts the errors were diluted to an almost infinitesimal degree. It had given him great pleasure to listen to the paper, and to be permitted to take part in the discussion.

Mr. Robert Lawson considered that five years was rather too short a period to be accepted as fairly deciding the point. The paper stated that diseases of the lungs had increased while phthisis had decreased, but that involved an understanding of what was meant by diseases of the lungs. Dr. Longstaff had included in diseases of the lungs bronchitis, which had decidedly increased, whereas pneumonia had diminished. In the first quinquennium from 1861 to 1879 , the death-rate from phthisis, males and females, throughout England, was 2,528 per million; in the next it had fallen to 2,499; in the next, to 2,2 I 9 ; in the next to 2,042, showing a distinct decrease; but taking diseases of the lungs (including bronchitis), the death-rate in the first quinquennium was 3,323 per million; in the next, 3,396; in the next, 3,687; and in the next, 3,800, showing a regular increase. Adding these numbers together, they gave for the first quinquennium, $5,85^{1}$; for the second, 5,895; for the third, 5,906; and for the fourth, 5,842. 
These results were not in accordance with the statement of Dr. Longstaff that the increase of lung disease was not equivalent to the reduction of phthisis. For the decennial periods the numbers were virtually the same, 5,873 for the first period and 5,874 for the second. By taking the longer period, some inequalities were got over which a shorter period introduced. Therefore, while admitting the value of Dr. Longstaff's remarks, he thought it would be better to wait a little longer to see how far the present low rate was borne out. He understood Dr. Longstaff to say that phthisis was a disease separate and distinct from other diseases of the lungs. A good many years ago he examined the returns of the army with regard to that very point, and the most striking fact he noticed was that, taking the returns of troops in this country and on all foreign stations singly, the frequency of phthisis in each was undoubtedly connected with the mortality from pneumonia. Among the civil population in this country, taking the period from 1850 to 1879 , in the first quinquennium there were 2.28 deaths from phthisis for every death from pneumonia; in the next there were 2.05 deaths to one; in the next 2.14 ; in the next 2.36 ; in the next 2.26 ; and in the next 2.05 ; showing no very material alteration in the relation between phthisis aud pneumonia, though both underwent considerable reduction during the period. It would seem therefore that there was really some connection between the prevalence of inflammatory affections of the lungs, and the prevalence of phthisis. He thought it was better to take the whole population, because in that case the incidence or power of the causes of pneumonia generally was shown, and separate portions of the population were subject to that incidence, though they themselves did not actually show this form of disease. Taking ages from 5 to 35 there was an extremely small proportion of deaths from pneumonia relatively to the other disease, from 1860-70, and from 1876-80, there were in the first period 9 deaths from phthisis among males and 14 among females to one in each case from pneumonia. In the subsequent period, pneumonia was a good deal more frequent, and among males there was $\mathrm{I}$ death from pneumonia to 6 from phthisis, and among females I to $9 \frac{1}{2}$. These periods were too short to make any decided deduction from, but taken with the other figures they showed that there was some relation between the prevalence of pneumonia generally and the prevalence of phthisis.

Mr. F. HENDRIKs thought the Statistical Society might some day suggest to the Government the advisability of amending the law of registration, by requiring that a certificate should be given gratis on the birth of any person. It should be printed upon the certificate that its preservation was a matter of importance. The price now charged for a certificate was a matter of consequence to the million, and the result was that in time through the want of a certificate a degree of uncertainty arose in the minds of the lower classes as to their exact ages. Even in the army it was found that great errors arose as to the ages of recruits through the absence of certificates. It was a great reflection upon England that we should

VOL. XLVII. PART II. 
in this matter be so far behind the other nations of Europe. Foreigners had been perfectly astounded to find that in this country there was nothing corresponding to the French acte de naissance, which is carefully kept because all Frenchmen knew that it had to be produced on certain occasions in their lives. In Sweden each parish had a registry of the births and deaths of all inhabitants kept in great detail, and if an individual moved to another parish he had to produce his acte de naissance, and have it entered in the parish to which he went. The gravest possible mistakes were made in England by stating ages in the census returns in a roughly approximate way. He agreed with Sir Rawson Rawson that there might be a kind of balance of errors, but that was not quite satisfactory, and it was not to our credit that such a state of things should exist. The certificate of birth should be given gratis, or at a mere nominal rate of charge on registration, and should be as religiously kept as marriage lines were in Scotland. On one occasion when some census returns were being discussed in the presence of the late Prince Consort, at a section of the London Statistical Congress, his Royal Highness, who seemed well acquainted with the more careful system of registration in Germany and France, was much surprised at the looseness of the system of registration in England. He (Mr. Hendriks) hoped that some day or other there would be an improvement in that respect.

Mr. N. A. HUMPHREYs said that servants and persons with no special knowledge were not now, except in rare cases, legal informants of registration of death. With regard to giving certificates of birth at the time of registration, he was afraid the English people would not be so careful of them as some foreign nations were, and that they would seldom be forthcoming when they were required.

Mr. A. 代. BAILEY said it was perfectly true that over a large collection of facts an average obtained, but in the matter of the return of the ages living there was a distinct tendency to error in one direction. For instance there was a great excess of ladies living between the ages of 20 and 25, and a corresponding diminution between 25 and 30 . It might be that the ages at death, which were in many cases given by nurses, might be as much in one direction as another; but on the other hand when people attained a certain age there was a strong tendency to make it greater than it really was, and that was not corrected by numbers.

The President said he was sure all present would agree in giving a cordial vote of thanks to Dr. Longstaff for his very interesting paper, which had stimulated an interesting discussion. Mr. Bailey had again given them the benefit of his opinions about the value of "ages" in the registrar-general's returns, and that had led to a very good discussion indeed; and on other points also the remarks which had been made would be very useful. Although he could not profess any special acquaintance with vital statistics, he could agree with Sir Rawson Rawson in expressing, as a statis- 
tician, accustomed to deal with statistical tables, a very strong opinion as to the value of the paper that had been read. He had seen very few papers to be compared with Dr Longstaff's for the excellence of the method which had been followed. The data might have been as imperfect as Mr. Bailey had described, but Dr. Longstaff had certainly made a good use of his material. He had stated his conclusions carefully, not pushing them to exaggeration in any way, and he had drawn attention to every kind of circumstance which would qualify the data. The main conditions of excellence in a statistical paper had thus been complied with. Having had the advantage of reading the paper beforehand, he (the President) had been paying some attention to the tables while Dr. Longstaff was reading it, and he thought they more than justified what Mr. Humphreys had said as to the very great pains the author must have taken. The tables were very clearly arranged, and the facts thus deduced from the registrar-general's returns must be of great value by way of record. Whatever might be the precise value of the facts at the present moment, there could be no doubt that some years hence the collection of them in sueh a way would be found very useful indeed by statisticians. The paper was in fact the kind of paper which it was most useful for the Society to have prepared and read at its meetings, and he thought they were much indebted to Dr. Longstaff for what he had done. With regard to the question which had been raised about the value of the average of ages, he should very much have liked it if Mr. Bailey and Mr. Hendriks had added to their observations by giving some idea of the nature of the variations from the true ages in the ages returned by the persons concerned. Those gentlemen stated that the returns were not to be relied upon. He presumed they were able to say so in a great many cases from having actually compared the ascertained ages of the people who had died with the ages that had been returned. Perhaps on some future occasion they would give the Society a statement of the degree of error in a great many cases. If they had done so at the present meeting, some means would have been afforded of judging of the limit of error which was likely to arise in records of this kind, and of saying with some definiteness whether the compensation of errors was likely to be material in this matter. Mr. Bailey had said that between 25 and 30 there was an actual ascertained tendency to give the wrong age; but if so much could be ascertained, it might also have been ascertained that at other ages there was really a compensation of errors which might be depended upon. He threw this out as a suggestion to Mr. Bailey, Mr. Hendriks, and other insurance friends; and he thought it would be very interesting indeed to have a statement of the number of cases in which the stated age was the actual age, and the cases in which there were variations from the true age, with, in the latter case, the degree or variation. If that were done, it might be found to indicate that, among a great many classes of the community at least, the age which the registrar-general obtained was to be depended upon to a very considerable extent at a great many ages. He had no doubt that Dr. Longstaff would reply to many questions which had been 
raised, but he should like to make one more remark. Whatever statements were made about the ages, they hardly affected many of the substantial conclusions of the paper, with reference for instance to the diminution of deaths from fever, and causes of that kind, where the diminution might be ascribed to sanitary influences. So far as he could judge, that part of the paper, as well as other parts, had not been challenged at all, and it seemed to him that it was one of the most useful parts. It established with some kind of certainty that those diseases which could be attacked by sanitary agencies had considerably diminished within the last twenty or forty years. That was really a very valuable conclusion, and it was certainly a great encouragement to sanitary reformers to persevere with their labours. No doubt it was true that the diminution of mortality was also due to some extent to better food, and to better medicinal appliances, and other causes; but still the fact was that the diseases which had diminished were those which might be attacked, so far as was known, by sanitary influences, and if over-crowding and similar evils had diminished during the last twenty years, and a diminution of mortality had followed, that was a very satisfactory result indeed of the figures which had been put before the Society. What Mr. Humphreys had said about there being apparently a decline in the mortality at the later ages in the last two or three years was very interesting. It was to be observed that all the causes of the improvement in the duration of life which had been at work during the last thirty or forty years had not as yet had time to tell. At first they might have merely effected a prolongation of feeble lives, so that there would be a tendency for a time for the mortality to increase in later ages; but when all these things had been a considerable time at work, there might be a tendency for the mortality at higher ages again to diminish. The experience of one or two years was not sufficient for a complete conclusion upon this point, but the facts stated by Mr. Humphreys were certainly interesting as an indication of what might be. The Society was also indebted to $\mathrm{Mr}$. Humphreys for his statement that the registrar-general was about to publish a factor for the different towns, allowing for the differing composition of the population as to age and sex, by which the rate of mortality might be made available for comparison with other rates. He thought that this addition to the information would be very valuable, and the Society ought by all means to recognise it. In conclusion, he had to ask the meeting to give a cordial vote of thanks to Dr. Longstaff for his very able and interesting paper.

Dr. LongstafF (in reply) said he had fully expected that his paper would be met with the line of objection that Mr. Bailey had brought forward, and he was very glad it had been met in that way, because, in the first place, if he might presume to say so, it was a very right and proper way of dealing with such a paper; and next, the views which Mr. Bailey represented were those that were widely prevalent. At the same time he might honestly say that no conclusion he had drawn in the paper had been in the slightest degree 
invalidated by any one of Mr. Bailey's criticisms, and that gentleman was hardly fair as to one or two points. In the first place, he (Dr. Longstaff) expressly did not take for his first period that which Mr. Humphreys took, because there was at that time a greater difference in diagnosis, and the care with which certificates were filled up was very much less than at the present time. One speaker objected that five years was two short a period; but he compared the period 1861-70 because for those ten years all the facts were already calculated in the registrar-general's report, with the latter half of the next decade, because that was the period of exceptionally low mortality. He thought it better to look and see in what respect it was low, and he carefully "hedged" by saying: "If this state of affairs should go on, such and such things would happen." With regard to the objections made about the uncertainty as to age, in the first place he included all ages over 75 together, and made no attempt to specify ages after that, because that was the point at which the errors most often occurred. The other critical period, from a medical point of view, was the first five years, and therefore he had grouped them together. As the greater part of the deaths occurred in the first two years, any error of a year or so in stating a child's age would have an insignificant effect upon his figures. Although his tables showed the increase of mortality at specified ages to amount to such and such a number per cent., he had drawn no special conclusions from these figures. $\mathrm{He}$ presumed that the average error in age would not amount, to more than from two to seven years. If the returns were taken, and from them a mathematical curve was drawn of the incidence of mortality at every age of life from one year up to a hundred, then there would be errors such as in the census were fully alluded to. But that did not in the slightest degree affect his figures. $\mathrm{He}$ thought that Mr. Humphreys had sufficiently answered Mr. Bailey as to the question of phthisis. Mr. Lawson might remember a paper that he (Dr. Longstaff) read before the Epidemiological Society, in which he showed that if a number of medical men signed a hundred certificates in which the death was attributed to phthisis, and another hundred in which death was stated to have resulted from bronchitis, they clearly meant something quite different in each case. He had analysed the returns in all sorts of ways. Representing them as curves, he found that the curves did not agree with one another, showing that, whatever overlapping there might be, there were in the main two distinct sets of facts. The curve of mortality from phthisis for forty years past was approximately a straight line, whereas the curve of mortality from diseases of the lungs was an irregular one, rising and falling year by year. In justice to himself and to the registrar-general's office, he wished to impress upon the meeting that the figures he had given might be relied on. He had made a graphic representation of the death-rates from a great number of causes for over forty years, and compared them two and two together. One evening after so comparing a number of curves for about an hour, he could not find the slightest resemblance between any of them, when suddenly he found that two agreed in a most remarkable manner. 
These two curves were for "apoplexy" and "mortification." It did not appear on the face of it that there was much connection between these, but he asked himself what was the cause of apoplexy and what was the cause of mortification. In both cases it was disease of the arteries, which in one instance prevented the proper circulation of blood, and in the other led to the rupture of an artery. The curves for cold winters and for these two diseases agreed. In cold winters there was greater blood pressure, resulting (where the arteries were diseased) in stagnation in the extremity, or in rupture of an artery of the brain. The connection thus shown between two causes from which comparatively so few died, showed that there must be some trnth in the registrar-general's returns. With regard to the matters to which Mr. Lawson called attention, he had elsewhere stated that the statistics of pneumonia had some sort of resemblance to those of phthisis, but not a very close one. Pneumonia occupied a sort of intermediate position between phthisis and bronchitis. Mr. Humphreys had very truly said that people had not tried to stop measles and whooping cough to a great extent. The credit of saying that lives between 25 and 35 were of special value, was due to Dr. Farr, who first called attention to it.

In conclusion, he thanked all present for the very kind way in which his paper had been received. 